\title{
Analysis of the metabolic pathways affected by hot- Humid or dry climate based on fecal metabolomics coupled with serum metabolic changes in broiler chickens
}

\author{
Ying Zhou \\ Chinese Academy of Agricultural Sciences Institute of Animal Science \\ Huchuan Liu \\ Qingdao University of Science and Technology \\ Minhong Zhang (D zmh66@126.com) \\ Chinese academy of agricultural sciences, Institute of animal sciences
}

\section{Research}

Keywords: Broilers, Hot humid climate, Hot dry climate, Metabolic pathways, Fecal Metabolomics, Serum metabolic changes

Posted Date: March 23rd, 2020

DOI: https://doi.org/10.21203/rs.3.rs-18654/v1

License: (c) (i) This work is licensed under a Creative Commons Attribution 4.0 International License. Read Full License

Version of Record: A version of this preprint was published at Poultry Science on November 1st, 2020. See the published version at https://doi.org/10.1016/j.psj.2020.07.039. 


\section{Abstract}

Background: Air temperature and humidity are two important climatic elements that affect animal welfare and health. The prevailing hot and humid or dry climate is one of the major constraints for optimum poultry production especially in the tropics and subtropical regions. Many studies have suggested that exposure hot-humid or dry climate is associated with a high risk of metabolic imbalance; however, the underlying metabolic route caused by low or high $\mathrm{RH}$ climate is not yet well understood. Therefore, we used a comprehensive UHPLC-Q-TOF/MS-based metabolic profiling of fecal samples to explore the effects of hot-humid and dry on metabolic pathway in broilers.

Results: Significant changes in the levels of 36 metabolites were detected. Evidence of changes in gluconeogenesis associated to pyruvate metabolism, galactose metabolism and $A B C$ transporter were observed. In addition, hot-humid and dry stress also affected protein translation process caused by aminoacyl-tRNA biosynthesis, which may be associated with protein synthesis and hormone secretion disorders. Furthermore, we observed significant changes in primary bile acid biosynthesis and taurine and hypotaurine metabolism, which indicated that fat synthesis was affected. We also observed significant changes in arginine and proline metabolism and histidine metabolism, which were associated with skin vasodilation and blood flow.

Conclusions: These results provide biochemical insights into metabolism route of hot-humid or dry climate.

\section{Background}

Air temperature and humidity are two important climatic elements that affect animal welfare and health. There is always a relationship between temperature and humidity and its effect on the body [1]. Over the past two decades, the global animal production has increased, especially in tropical and subtropical areas and more than $50 \%$ of total world meat originates from tropical and subtropical areas [2]. However, the prevailing hot and humid or dry climate is one of the major constraints for optimum poultry production in the tropics and subtropical regions. High ambient temperature and high relative humidity $(\mathrm{RH})$ or low $\mathrm{RH}$ occurring during the hot-humid or dry season have been shown to cause heat stress in broilers $[3,4]$. The fast growing commercial broiler chickens are particularly susceptible to heat stress to induce metabolic disorder [5, 6, 7]. In addition, global warming will further accentuate heat stress related problems. Therefore, elucidating the metabolic route is critical in hot-humid or dry climate, especially for providing a chemical route for the easing the adverse influence of $\mathrm{RH}$ because $\mathrm{RH}$ is seldom directly measured or managed and is not possible to control as narrowly as temperature [8].

A considerable body of evidence suggests that both high and low $\mathrm{RH}$ at high temperature decreased the growth performance of broiler $[9,10,11,12,13,14,15,16,17]$. At high temperature, heat production decreases while heat dissipation increases [18]. The main route of heat dissipation for birds under hot environment is evaporation. The amount of evaporate heat loss depends on air humidity and is 
suppressed when humidity rises $[18,19,20]$. Our preliminary research suggest that the decreased growth rate is associated with energy imbalance, as increased glucose consumption and reduced mitochondrial ATP production [17]. However, the exact metabolic route underlying the decreased growth and suppressed heat dissipation related to $\mathrm{RH}$ stress at high temperature still need to be elucidated.

Metabolomics is becoming an increasingly used tool for exhaustive studies of all metabolites contained in an organism [21]. It is known that external perturbations imposed on organisms can produce changes in their metabolites. These perturbations can be pathophysiological stimuli, environmental changes, nutritional stresses and genetic modification [22, 23]. Therefore, metabolomics can be used to identify novel and potential metabolite markers, and to explore molecular mechanisms and the response of metabolic pathways to different perturbations. Metabolomics is a novel technology with great potential for environmental changes research and provides a unique perspective on hot humid or dry-induced changes in cellular metabolism [24].

The fast growing nature of commercial broiler chickens prompted us to investigate different metabolic pathway after hot humid or dry stress. Here we assume that the metabolite profiles are associated with hot humid or dry induced pathophysiological processes. Therefore, to execute a large-scale detection of the metabolite features in fecal samples, untargeted fecal metabolomics based on ultra-high performance liquid chromatography coupled with quadrupole time-of-flight mass spectrometry (UHPLC-QTOF/MS) with high resolution, high throughput, and high sensitive technology was performed in this research $[25,26]$. An untargeted metabolomics work flow that acquires MS and MS/MS data sequentially was designed (Fig. 5). Quantitative information is extracted from MS data using XCMS Online and metabolite features are simultaneously characterized by matching the MS/MS data to the METLIN database [27]. With the approach of metabolomics analysis, the versatile effects of hot humid or dry on different metabolic pathways in fecal and more detail on the mechanisms of action after hot humid or dry stress could be observed.

\section{Materials And Methods}

\section{Chemicals}

All solvents used for sample preparation were of optimal grade for mass spectrometry. Acetonitrile was purchased from Merck (Merck, 1499230-935), formic acid was purchased from Fluka (Fluka, 06450), while ammonium acetate and ammonium fluoride were supplied by Sigma-Aldrich. Ultra-high purity water was prepared by Millipore-Q SAS 67120MOLS HEIM (France).

\section{Experimental design, animals, and management}

All experimental procedures involving the use of animals were approved by the the Animal Management Committee (in charge of animal welfare issues) of the Institute of Animal Science, Chinese Academy of Agricultural Sciences (IAS-CAAS, Beijing, China) and performed in accordance with the guidelines. Ethical 
approval on animal survival was given by the Animal Ethics Committee of IAS-CAAS, (Certification No.: IAS-2019-42).

One-day-old broiler chicks (Arbor Acres broilers) were reared in environmental chambers under continuous light for up to 3 weeks. At 21 days of age, 180 broilers with similar body weights ( $1.22 \pm 0.03 \mathrm{~kg}$ ) were randomly assigned to one of three treatments $(35 \%, 60 \%$, or $85 \%$ RH with an accuracy of $\pm 7 \%$ ) including six replicate cages with 10 birds per cage. Birds were kept at $20^{\circ} \mathrm{C}$ and $60 \% \mathrm{RH}$ for 1 week to adapt to the chamber environment. Temperature was then gradually increased by $3^{\circ} \mathrm{C}$ at $10: 00$ pm every 3 days from $20^{\circ} \mathrm{C}$ to $32^{\circ} \mathrm{C}$ (with an accuracy of $\pm 1{ }^{\circ} \mathrm{C}$ ) over the course of 15 days. The experiment period ends at the 42 day of age. The experimental diet was designed according to the National Research Council (NRC, 1994) guidelines. The composition and nutrient levels of the basal diets are shown in Table 1. Feed and tap water were available ad libitum. Dead birds were recorded daily, and chick weight and feed intake per cage were measured weekly to calculate the average daily gain (ADG), average daily feed intake (ADFI), feed conversion rate $(F / G)$ and mortality.

\section{Sample collections and preparations}

After the temperature was raised to $32^{\circ} \mathrm{C}$ for $48 \mathrm{~h}$, the skin temperature, rectal temperature and respiratory rate were measured.

The fecal were collected at 10:00 a. $\mathrm{m}$ ( $48 \mathrm{~h}$ after the temperature was raised to $32^{\circ} \mathrm{C}$ ). Then the fecal were immediately frozen in liquid nitrogen and then stored at $-80^{\circ} \mathrm{C}$ for metabolomics analysis. To facilitate individual sampling and quantitative collection of all voided feces without handling the animal, our method is similar to the one that be described by Touma et al (2003) [28]. Briefly, every ten broilers were housed individually in stainless steel wire cages $(87 \times 85 \times 40 \mathrm{~cm})$, which were placed in environment chambers of the same size. All excreta dropped through the bars of the steel wire cage and could be easily collected from the floor of the lower cage, which was completely covered with $1 \times 1 \mathrm{~m}$ black garbage bags. During each sampling, the black garbage bags were renewed.

At 42 days of age, birds were individually weighed following a 12-h fast and six birds were chosen from each chamber (one bird per cage). Blood samples were collected into tubes without anticoagulant and centrifuged at $1400^{\prime} \mathrm{g}$ for $10 \mathrm{~min}$ at $4^{\circ} \mathrm{C}$ for analysis of blood glucose, urea, AKP, CK, $\mathrm{T}_{3}, \mathrm{~T}_{4}$ and CORT. Birds were then sacrificed by cervical dislocation. The hypothalamus was taken and frozen at $-80^{\circ} \mathrm{C}$ for analysis of HSP70. The right breast muscle was removed and frozen at $-80^{\circ} \mathrm{C}$ for analysis of glycogen levels and av UCP mRNA expression. Liver samples were also taken and frozen at $-80^{\circ} \mathrm{C}$ for analysis of glycogen levels.

\section{Measurements of respiratory rate, core body temperature, skin temperature}

The specific method of skin temperature measurement is: using the infrared thermal imager FLIR E4 (thermal resolution $0.07^{\circ} \mathrm{C}$, accuracy $\pm 2 \%$ ) to shoot the side of the broiler head vertically, the shooting distance is $0.5 \mathrm{~m}$, shooting once every $3 \mathrm{~min}$, continuous Shoot $1 \mathrm{~h}$ and take 20 infrared photos per 
chicken. Through the FLIR Tools software analysis, the skin temperature of the leg, flipper, earlobe, comb, eyelids in each photograph was measured, and the average value of 20 data of the same chicken was taken as the true skin temperature value. Method for determining the core temperature: randomly select one chicken in each replicate of each group, and insert a digital thermometer (Model. JM 6200, resolution $\left.0.01^{\circ} \mathrm{C}\right) 5 \mathrm{~cm}$ long probe into the rectum almost, and record the value after stabilization. The core body temperature was recorded every $5 \mathrm{~s}$, and a total of 4 times were recorded, and the average value was taken. The respiratory rate was measured once every 10 minutes, and the number of breaths in broilers within 1 min was measured. A total of 6 breaths were collected, and the respiratory rate was the average of 6 breaths.

\section{Determination of glucose, glycogen, and urea}

Blood glucose concentrations and urea, and muscle and liver glycogen levels were determined using commercial assay kits (Nanjing Jiancheng Bioengineering Institute, Nanjing, China), according to the manufacturer's instructions.

\section{Hormone concentrations of serum and hypothalamus HSP70 concentrations}

Serum triiodothyronine $\left(T_{3}\right)$, thyroxine $\left(T_{4}\right)$, alkaline phosphatase (AKP), Creatine Kinase (CK), Corticosterone (CORT) and hypothalamus HSP70 were measured by commercial enzyme-linked immunosorbent assay (ELISA) kits specific for chicken (Nanjing Jiancheng Bioengineering Institute, Nanjing, China)), respectively, according to the manufacturer's instructions.

\section{RNA extraction and real-Time polymerase chain reaction (Real-Time PCR) assay}

Av UCP expression was determined using the Quantitative Real-time PCR. Total mRNA from the chest muscle was isolated using TRIzol reagent (CW0581; ComWin Biotech, Beijing, China). Aliquots of the PCR products were sequenced (Takara Bio, Shiga, Japan) to verify authenticity. The quantification of target gene expression was evaluated using the $2^{-\Delta \Delta C t}$ method.

\section{Extraction of fecal samples and quality control sample preparation}

Take about $10 \mathrm{~g}$ frozen samples in a vacuum freeze drier fully lyophilized (LGJ-18, Beijing honored cologne instrument technology co., LTD). Then take about approximately $25 \mathrm{mg}$ of each chicken lyophilized feces sample, add $1 \mathrm{~mL}$ of pre-chilled methanol/acetonitrile/water solution (2:2:1, v/v), vortex and mix, sonicate for $30 \mathrm{~min} /$ time, twice, and let stand at $-20^{\circ} \mathrm{C}$ for 60 minutes. Centrifuge at $14000 \mathrm{~g}$ for 20 min at $4{ }^{\circ} \mathrm{C}$, take the supernatant, dry under vacuum, add $100 \mu \mathrm{L}$ of acetonitrile aqueous solution (acetonitrile: water $=1: 1, \mathrm{v} / \mathrm{v}$ ) for re-dissolution during mass spectrometry, vortex, centrifuge at $14000 \mathrm{~g}$ at $4{ }^{\circ} \mathrm{C}$ for $15 \mathrm{~min}$, take the supernatant for UHPLC-Q-TOF/MS analysis.

In parallel to the preparation of the test samples, we prepared a bulk quality control (QC) sample. The QC samples served two purposes. The first purpose was to act as a regular quality control sample to monitor the LC-MS response in real-time. Secondly, after the response had been characterized, the QC samples 
were used as standards of unknown composition to calibrate the data [29, 30]. The QC sample was made by mixing equal volumes $(30 \mathrm{~mL})$ from each of the samples being analyzed to create a pooled sample of sufficient volume to provide enough QC samples for the analytical run. Each aliquot of this sample was treated in the same way as the test samples.

\section{UHPLC-MS analysis}

Metabolomics analysis was performed with an Agilent 1290 Infinity LC ultra-high pressure liquid chromatograph (UHPLC) (Agilent, Palo Alto, USA) equipped with an electrospray ionization source operating in positive and negative ion modes.

For HILIC separation, samples were analyzed using a $2.1 \mathrm{~mm} \times 100 \mathrm{~mm}$ ACQUIY UPLC BEH $1.7 \mu \mathrm{m}$ column (waters, Ireland). In both ESI positive and negative modes, the mobile phase contained A=25 mM ammonium acetate and $25 \mathrm{mM}$ ammonium hydroxide in water and $\mathrm{B}=$ acetonitrile. The gradient was $85 \%$ $B$ for $1 \mathrm{~min}$ and was linearly reduced to $65 \%$ in $11 \mathrm{~min}$, and then was reduced to $40 \%$ in $0.1 \mathrm{~min}$ and kept for $4 \mathrm{~min}$, and then increased to $85 \%$ in $0.1 \mathrm{~min}$, with a $5 \mathrm{~min}$ re-equilibration period employed.

The ESI source conditions were set as follows: Ion Source Gas1 (Gas1) as 60, Ion Source Gas2 (Gas2) as 60 , curtain gas (CUR) as 30 , source temperature: $600^{\circ} \mathrm{C}$, lonSpray Voltage Floating (ISVF) $\pm 5500 \mathrm{~V}$. In MS only acquisition, the instrument was set to acquire over the $\mathrm{m} / \mathrm{z}$ range 60-1000 $\mathrm{Da}$, and the accumulation time for TOF MS scan was set at $0.20 \mathrm{~s} / \mathrm{spectra}$. In auto MS/MS acquisition, the instrument was set to acquire over the $\mathrm{m} / \mathrm{z}$ range $25-1000 \mathrm{Da}$, and the accumulation time for product ion scan was set at 0.05 $\mathrm{s} /$ spectra. The product ion scan is acquired using information dependent acquisition (IDA) with high sensitivity mode selected. The collision energy (CE) was fixed at $35 \mathrm{~V}$ with $\pm 15 \mathrm{eV}$. Declustering potential (DP) was set as $\pm 60 \mathrm{~V}$.

For RPLC separation, a $2.1 \mathrm{~mm} \times 100 \mathrm{~mm}$ ACQUIY UPLC HSS T3 $1.8 \mu \mathrm{m}$ column (waters, Ireland) was used. In ESI positive mode, the mobile phase contained $A=$ water with $0.1 \%$ formic acid and $B=$ acetonitrile with $0.1 \%$ formic acid; and in ESI negative mode, the mobile phase contained $A=0.5 \mathrm{mM}$ ammonium fluoride in water and $\mathrm{B}=$ acetonitrile. The gradient was $1 \% \mathrm{~B}$ for $1.5 \mathrm{~min}$ and was linearly increased to $99 \%$ in $11.5 \mathrm{~min}$ and kept for $3.5 \mathrm{~min}$. Then it was reduced to $1 \%$ in $0.1 \mathrm{~min}$ and a $3.4 \mathrm{~min}$ of re-equilibration period was employed. The gradients were at a flow rate of $0.3 \mathrm{~mL} / \mathrm{min}$, and the column temperatures were kept constant at $25^{\circ} \mathrm{C}$. A $2 \mu \mathrm{L}$ aliquot of each sample was injected.

The ESI source conditions were set as follows: Ion Source Gas1 (Gas1) as 40, Ion Source Gas2 (Gas2) as 80 , curtain gas (CUR) as 30 , source temperature: $650^{\circ} \mathrm{C}$, lonSpray Voltage Floating (ISVF) $5000 \mathrm{~V}$ in positive mode, and $-4000 \mathrm{~V}$ in negative mode. In MS only acquisition, the instrument was set to acquire over the $\mathrm{m} / \mathrm{z}$ range 60-1000 Da, and the accumulation time for TOF MS scan was set at $0.20 \mathrm{~s} / \mathrm{spectra}$. In auto MS/MS acquisition, the instrument was set to acquire over the $\mathrm{m} / \mathrm{z}$ range 25-1000 Da, and the accumulation time for product ion scan was set at $0.05 \mathrm{~s} / \mathrm{spectra}$. The product ion scan is acquired using information dependent acquisition (IDA) with high sensitivity mode selected. The collision energy (CE) was fixed at $35 \mathrm{~V}$ with $\pm 15 \mathrm{eV}$. Declustering potential (DP) was set as $\pm 60 \mathrm{~V}$. 


\section{Data deconvolution and processing and statistical analysis}

For XCMS, the raw data files were first converted into the mzML format via ProteoWizard, and subsequently the converted files were imported into the XCMS software for nonlinear alignment in the time domain, automatic integration, and extraction of the peak intensities, with default parameter settings. The data were subsequently processed using XCMS for peak alignment and data filtering. MetaboAnalyst 2.0 (http://www.metaboanalyst.ca) was used for the statistical analysis. Principle component analysis (PCA) and hierarchical clustering were performed for the unsupervised multivariate statistical analysis. Partial-least squares discrimination analysis (PLS-DA) was performed as a supervised method to identify the important variables with discriminative power. PLS-DA models were validated based on the multiple correlation coefficient (R2) and cross-validated R2 (Q2) in crossvalidation and permutation tests by applying 2000 iterations $(P>0.001)$. The significance of the biomarkers was ranked using the variable importance in projection (VIP) score $(>1)$ from the PLS-DA model. For the univariate analysis, candidate specific biomarkers were determined using singledimensional statistical analysis for one-way Anova analysis. $P<0.05$ was considered to be statistically significant.

\section{Metabolites identification and pathway analysis}

The Metlin database was used to identify potential specific biomarker candidates based on their MS signature and tandem mass spectrometry (MS/MS) spectra, as well as eventual contaminants. Identification of potential biomarkers was carried out by searching METLIN (http://metlin.scripps.edu/), HMDB (http://www.hmdb.ca/), KEGG (http://www.genome.jp/kegg/), MassBank (http://www.mass bank.jp/), LIPIDMAPS (http://www.lipidmaps.org/) and Chemspider (http://www.chemspider.com) using the exact molecular weights or the MS/MS fragmentation pattern data, and a literature search was conducted to identify the affected metabolic pathways and to facilitate further biological interpretation. Mass accuracy tolerance within $25 \mathrm{ppm}$ was used as the mass window for the database search. For confirmation of the metabolite identities using an authentic chemical standard, the MS/MS fragmentation pattern of the chemical standard was compared with that of the candidate metabolite under the same LC-MS conditions to reveal any matching. In the case of unknown metabolites, molecular formulae were generated using Mass Profiler Professional (Agilent Technologies).

\section{Statistical analysis}

Data on growth performance, respiratory rate, core body temperature, skin temperature of leg, flipper, earlobe, comb, eyelids, blood glucose, muscle glycogen, liver glycogen, $T_{3}, T_{4}, C O R T, A K P, C K, H S P$ 70, av UCP were analyzed using the one-way anova procedure in SAS version 9.2 (SAS Institue. Inc., Cary, NC, USA). Differences among means were tested using Duncan's multiple range test. Replicate cage served as the experimental unit and $P<0.05$ was considered to be statistically significant.

\section{Results}




\section{Growth performance}

RH stress reduced the growth performance in the experiment broilers (Fig. 1). 85\% RH decreased $(P<$ $0.02)$ the $\mathrm{ADFI}$, both $35 \%$ and $85 \% \mathrm{RH}$ decreased $(P<0.01)$ the ADG.

\section{Glucose, glycogen, urea levels}

RH had effects $(P<0.05)$ on the blood glucose, muscle glycogen and blood Urea, and had no effect $(P>$ 0.06 ) on the hepatic glycogen (Fig. 2). $85 \%$ and $35 \%$ RH increased $(P<0.0001)$ the blood glucose, and the $85 \% \mathrm{RH}$ further increased $(P<0.05)$ it compared to the $35 \% \mathrm{RH}$, and both decreased $(P<0.05)$ the muscle glycogen. $35 \% \mathrm{RH}$ increased $(P=0.05)$ the blood Urea.

\section{Serum hormones and hypothalamus HSP70 concentrations}

RH had effects $(P<0.05)$ on the $\mathrm{T}_{3}, \mathrm{~T}_{4}$, CORT, AKP and CK (Fig. 3). 85\% RH increased $(P<0.03)$ the $\mathrm{T}_{3}$ compared to the $35 \% \mathrm{RH} .85 \%$ and $35 \% \mathrm{RH}$ increased $(P<0.03)$ the $\mathrm{T}_{4}$ in serum. $35 \% \mathrm{RH}$ decreased $(P<$ $0.0001)$ the CORT in serum compared to the other groups. $85 \% \mathrm{RH}$ increased $(P=0.0298)$ the AKP in serum compared to the other groups. $85 \%$ and $35 \% \mathrm{RH}$ increased $(P<0.02)$ the CK in serum. $35 \% \mathrm{RH}$ decreased $(P=0.0364)$ the HSP 70 in hypothalamus compared to the other groups.

\section{Av UCP expression, respiratory rate, skin temperature and core body temperature}

$\mathrm{RH}$ had an effect $(P<0.05)$ on the av UCP expression (Fig. 4A). Compared with the $60 \% \mathrm{RH}$, both $85 \%$ and $35 \% \mathrm{RH}$ increased $(P<0.05)$ the av UCP expression. RH had also effects $(P<0.01)$ on the respiratory rate, skin temperature and core body temperature (Fig. 4B-H). Compared with the $60 \% \mathrm{RH}, 85 \% \mathrm{RH}$ increased $(P<0.0001)$ the respiratory rate, and $35 \% \mathrm{RH}$ decreased $(P<0.0001)$ it; However, $85 \% \mathrm{RH}$ decreased $(P<$ $0.01)$ the skin temperature (leg, flipper, earlobe, comb, eyelid), and $35 \% \mathrm{RH}$ increased $(P<0.01)$ it. And $85 \% \mathrm{RH}$ increased $(P<0.05)$ the core body temperature.

\section{Fecal metabolic profiling by UHPLC-Q-TOF/MS}

The stability of the analytical method is crucial for obtaining valid metabolomics data. To validate the system's performance during sample analysis, a pooled QC sample was applied that was a representative "mean" sample including all analytes used during the analysis [31]. QC samples were handled as real samples and inserted every five samples into the electrospray ionization (ESI) positive or negative analysis batch to monitor the stability of the instrument. The similarity of the QCs included the peak shape, separation degrees, retention times, and intensity distribution of the metabolites involved in the profiles. The results indicated that the method was robust with good repeatability and stability, rather than the product of artefacts arising from technical errors, and was suitable for the measurement of the samples in this study.

Using XCMS software for peak detection, 10113 peaks of positive ions and 10685 negative ions in RPLC, 4186 peaks of positive ions and 10014 negative ions in HILIC were obtained. Although fewer peaks were 
extracted from the HILIC column, these peaks can also be used as a comprehensive fecal metabonomics profiling as well as RPLC. The variables were exported into MetaboAnalyst for multivariate data analysis to detect any inherent trend within the date. All fecal samples were divided into three groups: G1:35\% RH (hot-dry) group, G3: 60\% RH (hot-mid) group and G5: 85\% RH (hot-humid) group. Principal component analysis (PCA) was carried out using these molecular features on all the sample groups from the study including conditioning runs and QC samples. The distribution of metabolic profiles for the QC samples in PCA can be seen in Fig. 6. All of the QC injections (Green) were clustered tightly in PCA space. The consistency of the repeated QC injections and reliable data quality across all the samples demonstrated the suitability of the method for metabolic profiling studies during the experiment.

The separation conditions of fecal samples on both columns were optimized. Typical UHPLC-Q-TOF/MS Total Ion Current (TIC) chromatograms of fecal samples from the G1 group, G3 group and G5 group in both positive-and negative-ion modes were shown in Fig. 7-8. Under experimental conditions, the TIC shared considerable similarity, and the peak shape of each substance was good and the peaks well separated from each other, indicating that the chromatographic and MS conditions were suitable for the measurement of the samples in this study. And RPLC has better retention for weakly polar component. In addition, HILIC allows varied selectivity and the better retention for polar analytes. The integrated utilization of two separation modes could enlarge metabolite identification.

\section{Normalization and multivariate statistical analysis}

It is often necessary to normalize metabolomics data before starting any kind of statistical analysis. Normalization can reduce any systematic bias or technical variation, and metabolite concentrations usually span several orders of magnitude, which can lead to misidentification of significant changes. In our study, the " $50 \%$ rule" was applied to remove the missing values, and the results indicated that the metabolomics data presented a normal distribution after normalization processing (Fig. 9).

\section{Principal component analysis (PCA)}

To determine whether the global metabolite fingerprints in fecal differed among the hot humid (G5), mid (G3) or dry (G1) treatments, we evaluated the separation among the three treatments in both ion modes using unsupervised PCA. PCA is an unsupervised clustering or classification method. PCA showed that $42.4 \%$ of the total variance in the data was represented by the first two principal components in the positive mode in HILIC (Fig. 10A). The total variance in the data represented by the first two principal components in the negative mode in HILIC was 39.6\% (Fig. 10B). However, to RPLC, in the positive and negative were $35.9 \%, 36 \%$, respectively (Fig. 10C; Fig. 10D). In these plots, compared to G1 and G3 group, G5 group showed a slight but not significant separation trend in the 2D-PCA score plots. The plot revealed that the trend of $\mathrm{G} 1$ and $\mathrm{G} 3$ separation was not obvious in positive and negative ion mode data, but there was a significant trend in G5 group, which indicated that G5 group had some changes in metabolic profile.

\section{Partial least squares discrimination analysis (PLS-DA)}


To further identify ion peaks that could be used to discriminate among the among the hot humid (G5), mid (G3) or dry (G1) treatments, a supervised PLS-DA model was established that was more focused on the actual class discriminating variation compared to the unsupervised PCA model. PLS-DA is a supervised clustering or classification method. PLS-DA projects the data into a low-dimensional space that maximizes the separation among different groups in the latent variables. As can be seen, from the Figure 11, satisfactory clustering trends among the G1, G3, and G5 groups were observed in the scores plot, indicating that the possibility of using fecal metabonomics for evaluating stress. In PLS-DA, R2 (cum) and Q2 (cum) parameters were used for the evaluation of the models, indicating the fitness and prediction ability, respectively. Q2 (cum) $>50 \%$ shows that the mode is useful; if the Q2 (cum) $>90 \%$, the mode is excellent. In Figure.10, the classification resulted in three components with excellent modeling and predictive abilities. From these results, we can find that the PLS-DA models were valid for all four modes.

\section{Detection and identification of differential metabolites}

To identify which variables were responsible for this separation, a study on the variable influence on the projection (VIP) parameter was conducted. VIP values calculated using the PLS-DA model revealed which variables (metabolites) had the greatest influence on the discrimination between the fecal metabolic samples. Potential metabolites were selected based on the VIP score $(>1)$. For the univariate analysis, candidate specific biomarkers were determined using single-dimensional statistical analysis for one-way ANOVA analysis. The critical $P$-value was set to 0.05 for the significantly differential variables in this study. We searched for candidates from the freely accessible databases of HMDB (http://www.hmdb.ca), METLIN (http://metlin.scripps.edu) and KEGG (http://www.kegg.jp) by their masses, then, MS/MS analyses were performed, and due to the possible fragment mechanisms, items without given mass fragment information were removed from the candidate list and only the most probable items were left. By comparing the retention times and mass spectra of the authentic chemicals as well as the standard MS/MS spectra from the above databases, 36 significantly differential fecal metabolites were selected as potential biomarkers related to hot-humid, mid or dry stress (Table 4-5). Table 4-5 also shows the tentative identification of these metabolites (compound name, molecular formula, adduct). The metabolites of Uracil, Hydroxyproline, 2-Isopropylmalic acid, Xanthine, Benzoic acid, 1,4Dihydroxybenzene, DL-Methionine sulfoxide, Thymine, Adenine, Taurocholate, etc., may be potential biomarkers for hot-humid, mid or dry stress based on their VIP scores. The greater VIP score of the metabolite, the greater contribution to the separation of sample classification, and therefore the metabolite may be a potential biomarker [32, 33].

In general, when the screening of the metabolites was reasonable and accurate, the samples from one group appeared in one cluster. Metabolites gathered in the same cluster had similar patterns of expression, which may indicate that they were involved in adjacent or close steps in the overall process of metabolism. The tree structure on the left side of Fig.12 represented the clustering relationships of each metabolite, and the tree structure at the top represents the clustering relationships of each sample. 
Hierarchical clustering results also showed that significantly different metabolites existed among the three groups, although some metabolites also showed similarities.

\section{Potential metabolic pathways related to the hot-humid, mid or dry stress}

Pathway analysis has been proven to be an invaluable tool for understanding complex relationships among genes and proteins $[34,35]$. Therefore, to identify possible pathways relevant to the hot-humid, mid or dry stress, all of the attributed metabolites were subjected to Metaboanalyst 3.0, a free online tool based on the high-quality KEGG metabolic pathways database (www.metaboanalyst.ca). The influenced metabolic pathway was set as $P<0.05$. Hence, 13 metabolic pathways were detected as potential metabolic pathways for the hot-humid, mid or dry stress (Fig. 13). With the power of this metabolomics analysis, the versatile effects of hot-humid, mid or dry stress on the different metabolic pathways in fecal could be observed in an untargeted manner. The results showed that the potential biomarkers were responsible for primary bile acid biosynthesis, Taurine and hypotaurine metabolism, Phenylalanine metabolism, Histidine metabolism, Tyrosine metabolism, Pyruvate metabolism, beta-Alanine metabolism, etc. (Table 6). The different metabolic pathways were likely due to the dynamic process of hot-humid, mid or dry stress and might be closely associated with RH stress.

\section{Discussion}

To the best of our knowledge, this is the first study to identify metabolic pathway associated with the hothumid or dry climate in broilers. In our study, we analyzed the main pathways affected by hot-humid, mid or dry stress. Such analysis enabled us to explain the route of how hot-humid or dry climate decreased growth and supressed heat dissipation in broilers at the metabolic levels.

High $\mathrm{RH}$ or low $\mathrm{RH}$ at high temperature increased glyconeogenesis and made heat dissipation disorder, and decreased broiler growth. We found significant reduction of average daily gain, increase of glucose and urea in blood (low RH), decrease of respiratory and increase of skin temperature (low RH), increase of respiratory rate and decrease of skin temperature (high $\mathrm{RH}$ ), increase the expression of av UCP in muscle and body temperature in the low and high RH group, as presented in Fig. 1, Fig. 2, Fig. 4, respectively. However, the mechanism of their metabolic caused by RH was obscure. Therefore, in the subsequent step, the metabolic pathway affected by RH was investagated. As show in Fig. 13 metabolic pathways were detected, which were related to the decreased growth and supressed heat dissipation. We found that pyruvate metabolism, galactose metabolism and ABC transporter, aminoacyl-tRNA biosynthesis, primary bile acid biosynthesis and taurine and hypotaurine metabolism, arginine and proline metabolism and histidine metabolism were affected by $\mathrm{RH}$. All of these pathways were associated with growth decline and heat dissipation.

Pyruvate, an intermediate metabolite of the gluconeogenesis pathway, plays an important role in energy metabolism [36], and is the end product of glycolysis and the starting substrate for the tricarboxylic acid (TCA) cycle [37]. Previous studies showed that creatine pyruvate improved the energy status, increased the gene expression of glucose transporter proteins, and facilitated glycolysis in breast muscle [38]. In the 
present study, succinic acid, pyruvic aldehyde and 2-isopropylmalic acid were involved in the pyruvate metabolic pathway. Succinic acid is an important product in the process of the tricarboxylic acid cycle. Pyruvic aldehyde is a metabolite in the glycolysis process. These substances were important metabolites in the process of glucose metabolism, which indicated that RH stress can cause changes in the glucose metabolism of broilers, and combined with our biochemical indicators, hepatic glycogen, muscle glycogen, blood glucose and urea of broilers have also changed, further indicated that $\mathrm{RH}$ caused the increased glyconeogenesis. In addition, the pathway involved in glucose metabolism is galactose metabolism. Its metabolism was mainly through galactose kinase, galactose-1-phosphate uridine transferase, and urine. The glycoside diphosphate galactose-4-differase and its catalyzed enzymatic reaction were converted to glucose and utilized. In this study, it was found that a-D-glucose 1-phosphate, stachyose and d-(+)-meliose in the metabolites were involved in the galactose metabolism pathway. At the same time, it was found that the RH stress caused a change in the metabolism of the adenosine triphosphate binding cassette transporter ( $A B C$ transporter). The $A B C$ transporter was named for its binding cassette containing adenosine diphosphate (ATP). ABC transporter is a membrane integrin that utilizes the energy of hydrolyzing ATP to transport transmembrane transport of various biomolecules in solute. The substrates for transport include: sugars, amino acids, metal ions, peptides, proteins, cellular metabolites and drugs. Wait. In this study, L-glutamine, hydroxyproline, D-(+)-melose, D-galacturonic acid and L-phenylalanine were found to be involved in the $A B C$ transporter metabolic pathway. Alanine is a precursor of synthetic carnosine, which acts as an ionic buffer and improves glucose metabolism [39]. In this study, uracil and L-carnosine were found to be involved in the $\beta$-alanine metabolic pathway. The above results indicated that $\mathrm{RH}$ caused increased glyconeogenesis in broilers.

In the process of biotransformation, each tRNA molecule needs to bind to the corresponding amino acid, and then transport these amino acids to the ribosome for protein synthesis. The bond formed between the amino acid and the tRNA is a high energy bond, called an aminoacyl-tRNA bond, which plays an important role in transport. If the aminoacyl-tRNA synthesis is impaired, the synthesis of the protein will inevitably be affected, which will further affect the hormones secretion, enzyme synthesis, protein synthesis, cell proliferation and so on. In the present study, three metabolites of L-methionine, L-glutamine and L-phenylalanine were involved in the aminoacyl-tRNA anabolic pathway, which indicated that the protein translation process is involved in the $\mathrm{RH}$ stress and the various hormones that cause secretion are hampered, and at the same time we measured the amount of some serum enzymes, and found that the contents of alkaline phosphatase, creatine kinase, $T_{3}, T_{4}$, CORT and HSP 70 changed. The above results indicated that $\mathrm{RH}$ caused protein synthesis and hormone secretion disorders.

Taurine, 2-aminoethanesulfonic acid, is an abundant $\beta$-amino sulfonic acid in many excitable tissues. It presents as a free form, accounting for approximately $0.1 \%$ of the total body mass [ $40,41,42]$. Previous studies indicate that taurine exerts important physiological functions in modulation of intracellular calcium concentration, ion channel function, glucose and lipid homeostasis, cellular redox homeostasis, and anti-antioxidant and anti-inflammatory responses $[43,44,45]$. In this study, significant changes were observed in the metabolic pathway of taurine and hypotaurine, and taurocholate was involved in this 
pathway. In addition, it has also been found that the biosynthetic metabolic pathway of primary bile acids has also changed significantly. There were 9 (taurine deoxycholate, tauro-goose (deoxy) cholate, taurocholate, cholic acid etc.) metabolites enriched in this pathway, it can be inferred that RH stress can cause changes in the metabolism of bile acids in the liver, affecting the absorption of lipids and fatsoluble vitamins, which in turn influences the synthesis of fat, thus reducing the growth of broilers.

Tyrosine is a synthetic precursor of the neurotransmitters norepinephrine, dopamine, and adrenergic receptors. These neurotransmitters play important neurotransmitters in the sympathetic nervous system. Once damaged, the overall signal transmission is affected [46, 47]. In addition, tyrosine is a synthetic precursor of hormones, thyroids, and colorants (melanin) [48]. It can also be converted into dopamine or catecholamine for signal transduction, or it can form a protein activating enzyme with a phosphate group, regulate the activity of the enzyme, and provide energy $[49,50,51]$. The catabolism of tyrosine involves the enzymatic, energy metabolism of the Krebs cycle. In this study, succinic acid, maleic acid, 4hydroxycinnamic acid, tyramine and 1,4-dihydroxybenzene were found to be involved in the tyrosine metabolic pathway. In addition, phenylalanine is an essential aromatic amino acid. Under normal circumstances, it is mainly metabolized in the liver and other tissues to produce tyrosine, and then in the nervous system. And the adrenal medulla synthesize certain hormones, neurotransmitters such as dopamine (DA), norepinephrine (NE), epinephrine (E) and melanin in the skin. Therefore, the growth and development of the body and the maintenance of normal physiological functions require a stable state of phenylalanine metabolism. Insulin promotes uptake and utilization of branched-chain amino acids in muscle tissue and lowers blood glucose levels. Studies have found that [52], phenylalanine can promote insulin secretion, which is believed to be related to the increase in insulin levels as a nutrient supply to phenylalanine. In this study, it was found that succinic acid, 4-hydroxycinnamic acid, L-phenylalanine, benzoic acid, 3-phenylpropionic acid and 2-hydroxyphenylacetic acid participate in the phenylalanine metabolic pathway. This also showed that RH stress can cause changes in hormones and glucose metabolism.

The maintenance of normal body temperature depends on the dynamic balance of the body's heat production and heat dissipation. The body continuously generates heat during metabolism to maintain body temperature. At the same time, the heat in the body is brought to the body surface by circulating blood, and the heat is dissipated by evaporation. Evaporative cooling depends on the temperature difference between the skin and the ambient temperature, which in turn is controlled by the blood flow of the skin. Therefore, the body can adjust the amount of body heat loss by changing the functional state of the skin blood vessels. Arginine is a precursor for the synthesis of many biomolecules, including ornithine, polyamines (putrescine, spermine and spermidine), proline, glutamine, creatine, agmatine, NO and proteins. Among them, NO is an endothelium relaxing factor released by vascular endothelial cells, which determines the blood flow of the skin. In this study, hydroxyproline, 4-mercaptobutyric acid, Dvaline, and $\mathrm{N}$ - $\omega$-hydroxyarginine were found to be involved in the arginine and proline metabolic pathways. In addition, histamine is one of autologous active substances and is abundant in the skin, bronchial mucosa, intestinal mucosa and nervous system. The receptor that binds histamine to vascular smooth muscle (H1R) causes vasodilation and local edema. Histamine causes contraction of the 
tracheal smooth muscle of the lung to cause airway stenosis and difficulty breathing, intestinal smooth muscle contraction lowers blood pressure and increases many physiological responses such as tachycardia. In this study, L-carnosine, histamine, 3-methylhistidine, and 1-methylhistamine were found to be involved in the histidine metabolism pathway. It can be seen that the RH stress would cause the blood flow of the skin to change, thereby changing the amount of heat dissipation and causing changes in body temperature. At the same time, we determined that the respiratory rate, body temperature and skin temperature of broiler had changed (Fig. 4). In addition, Av UCP is a potential indicator of the energy inefficiency of ATP synthesis and energy metabolism [53]. Both high and low RH increased the expression of av UCP, which meant that the more in heat production to maintain body temperature, the less energy was used for growth.

\section{Conclusion}

In conclusion, this study investigated the metabolic signatures of the hot-humid, mid or dry stress broilers using an untargeted metabonomics platform and combined with the serum metabolic changes or heat dissipation. Results from this global metabolic profiling study revealed the metabolic profile (Fig. 14) in hot-humid or dry stress broilers that might account for the pathway of pyruvate metabolism, galactose metabolism and ABC transporter, aminoacyl-tRNA biosynthesis, primary bile acid biosynthesis and taurine and hypotaurine metabolism, and also revealed the heat dissipation disorder that might due to arginine and proline metabolism and histidine metabolism. Understanding the targets of these metabolites and metabolic pathway may improve our understanding of the adverse of hot-humid or dry climate on growing fast commercial broilers in the metabolic level and also the regulation of $\mathrm{RH}$ in poultry.

\section{Declarations}

\section{Acknowledgements}

Not applicable.

\section{Authors' contributions}

The article was mainly conceived and designed by $Y Z, M Z, Y Z$ performed the experiments and analyzed the data. The manuscript was mainly written by $\mathrm{YZ}$. MZ and HL revised it critically for important content. All authors have read and approved the final manuscript.

\section{Funding}

This work was supported by the Key National Research and Development Program project of China (2016YFD0500509).

\section{Availability of data and materials}


All data generated or analyzed during this study are available from the corresponding author on reasonable request.

\section{Ethics approval and consent to participate}

This experiment was approved by the the Animal Management Committee (in charge of animal welfare issues) of the Institute of Animal Science, Chinese Academy of Agricultural Sciences (IAS-CAAS, Beijing, China) and performed in accordance with the guidelines. Ethical approval on animal survival was given by the Animal Ethics Committee of IAS-CAAS, (Certification No.: IAS-2019-42).

\section{Consent for publication}

Not applicable.

\section{Competing interests}

The authors declare that they have no competing interests.

\section{References}

1. Tseliou A, Tsiros IX, Lykoudis S, Nikolopoulou M. An evaluation of three biometeorological indices for human thermal comfort in urban outdoor areas under real climatic conditions. Build Environ. 2010;45 (5):1346-1352.

2. FAO statistics 2010. http://faostat.fao.org/

3. Ayo JO, Obidi JA, Rekwot PI. Effects of heat stress on the well-being, fertility and hatchability of chickens in the Northern Guinea Savannah zone of Nigeria: A review. ISRN Vet Sci. 2011;10.

4. Minka NS, Ayo JO. Assessment of thermal load on transported goats administered with ascorbic acid during the hot-dry conditions. Int J Biometeorol. 2012;56:333-341.

5. Yousaf A, Shahnawaz R, Jamil T, Mushtaq A. Prevalence of coccidiosis in different broiler poultry farms in Potohar region (distract Rawalpindi) of Punjab- Pakistan. J D Vet Anim Res. 2018;7:87-

6. Yousaf A, Tabasam MS, Memon A, Rajput N, Shahnawaz R, Rajpar S, Jamil T, Mushtaq M.

Prevalence of ascaridia galli in different broiler poultry farms of potohar region of rawalpindipakistan. J D Vet Anim Res.2019;8:71-

7. Olubodun JO, Zulkifli I, Farjam AS, Hair-Bejo M, Kasim A. Glutamine and glutamic acid supplementation enhances performance of broiler chickens under the hot and humid tropical condition. Ital J Anim Sci. 2015;14:3263.

8. Dawkins MS, Donnelly CA, Jones TA. Chicken welfare is influenced more by housing conditions than by stocking density. Nature. 2004;427:342-344.

9. Milligan JL, Winn PN. The influence of temperature and humidity on broiler performance in environmental chambers. Poult Sci. 1964;43:817-824. 
10. Adams RL, Rogler JC. The effects of dietary aspirin and humidity on the performance of light and heavy breed chicks. Poult Sci.1968;47:1344-1348.

11. Reece FN, Deaton JW, Kubena LF. Effects of high temperature and humidity on heat prostration of broiler chickens. Poult Sci. 1972;51:2021-2025.

12. Misson BH. The effects of temperature and relative humidity on the thermoregulatory responses of grouped and isolated neonate chicks. J Agr Sci.1976;86:34-43.

13. Yahav S, Goldfeld S, Plavnik I, Hurwitz S. Physiological responses of chickens and turkeys to relative humidity during exposure to high ambient temperature. J Therm Biol.1995;20:245-253.

14. Yahav S. Relative humidity at moderate ambient temperatures: its effect on male broiler chickens and turkeys. Bri Poult Sci. 2000;41:94-100.

15. Zhou Y, Zhang MH, Feng JH.Effects of Relative Humidity on Body Heat Regulation and HSP70 Content of Hypothalamus in Broiler Chicken at increasing temperature. Chinese $\mathrm{J}$ Anim Nutr. 2017;28:60-68 (in chinese)

16. Zhou Y, li XM, Zhang MH, Feng JH. Effect of relative humidity at either acute or chronic moderate temperature on growth performance and droppings' corticosterone metabolites of broilers. $\mathrm{J}$ Integr Agr.2019;18:152-159.

17. Zhou Y, Zhang MH, Feng JH, Diao HJ. Effect of relative humidity at chronic temperature on growth performance, glucose consumption, and mitochondrial ATP production of broilers. J Integr Agr. 2019;18:1321-1328.

18. Lin H, Zhang HF, Du R, Gu XH, Zhang ZY, Buyse J, Decuypere Thermoregulation responses of broiler chickens to humidity at different ambient temperatures. II. Four weeks of age, Poult Sci.2005;84:1173-1178.

19. Chwalibog A, Eggum BO. Effect of temperature on performance, heat production, evaporative heat loss and body composition in chickens. Arch Geflugelkd. 1989;53:179-184.

20. Nichelmann M, Tzschentke B, Burmeister A. Evaporative Warmeabgabe des Geflugels bei Hoher Relativer Luftfeuchtigkeit. Arch Geflugelkd.1991;55:110-115.

21. Lau SK, Lam CW, Curreem SO, Lee KC, Lau CC, Chow WN, Ngan AH, To KK, Chan JF, Hung IF, Yam WC, Yuen KY, Woo PC. Identification of specific metabolites in culture supernatant of Mycobacterium tuberculosis using metabolomics: exploration of potential biomarkers. Emerging Microbes Infect. 2015;4:e6.

22. Navarro-Reig M, Jaumot J, García-Reiriz A, Tauler R. Evaluation of changes induced in rice metabolome by $\mathrm{Cd}$ and $\mathrm{Cu}$ exposure using LC-MS with XCMS and MCR-ALS data analysis strategies. Anal Bioanal Chem.2015;407:8835-8847.

23. Nicholson JK, Lindon JC, Holmes E. 'Metabonomics': understanding the metabolic responses of living systems to pathophysiological stimuli via multivariate statistical analysis of biological NMR spectroscopic data. Xenobiotica.1999;29:1181-1189.

24. Booth SC, Workentine ML, Weljie AM, Turner RJ. Metabolomics and its application to studying metal toxicity. Metallomics. 2011;3:1142-1152. 
25. van der Greef J, van Wietmarschen $\mathrm{H}$, van Ommen B, Verheij E. Looking back into the future: 30 years of metabolomics at TNO. Mass Spectrom Rev. 2013;32:399-415.

26. Plumb RS, Granger JH, Stumpf CL, Johnson KA, Smith BW, Gaulitz S, Wilson ID, Castro-Perez J. A rapid screening approach to metabonomics using UPLC and oa-TOF mass spectrometry: application to age, gender and diurnal variation in normal/Zucker obese rats and black, white and nude mice. Analyst. 2005;130:844-849.

27. Benton HP, Ivanisevic J, Mahieu NG, Kurczy ME, Johnson CH, Franco L, Rinehart D, Valentine E, Gowda H, Ubhi BK, Tautenhahn R, Gieschen A, Fields MW, Patti GJ, Siuzdak G. Autonomous metabolomics for rapid metabolite identification in global profiling. Anal Chem. 2015;87:884-891.

28. Touma C, Sachser N, Möstl E. Effects of sex and time of day on metabolism and excretion of corticosterone in urine and feces of mice. Gen Comp Endocr. 2003;130:267-278.

29. Van Der Greef J, Martin S, Juhasz P, Adourian A, Plasterer T, Verheij ER, McBurney RN. The art and practice of systems biology in medicine: mapping patterns of relationships. J Proteome Res. 2007;6:1540-1559.

30. Gika HG, Theodoridis GA, Wingate JE. Within-day reproducibility of an HPLC- MS-based method for metabonomic analysis: application to human urine. J proteome Res. 2007;6:3291-3303.

31. Sangster T, Major H, Plumb R, Wilson AJ, Wilson ID. A pragmatic and readily implemented quality control strategy for HPLC-MSand GC-Ms based metabonomic analysis. Analyst. 2006, 131:10751078.

32. Ma X, Meng L, Li X, Li L, Wang Y, Mao X. Urine metabonomics study on diabetes patients by UPLC/QTOF MS. J Instrum Anal. 2014;33:621-627.

33. Wang H, Liu Z, Wang S, Cui D, Zhang X, Liu Y, Zhang Y. UHPLC-Q-TOF/MS based plasma metabolomics reveals the metabolic perturbations by manganese exposure in rat models. Metallomics. 2017;9:192-203.

34. Goffard N, Frickey T, Weiller G. Path Express update: the enzyme neighbourhood method of associating gene expression data with metabolic pathways. Nucleic Acids Res. 2009;37:335-339.

35. Hu Z, Hung JH, Wang Y, Chang YC, Huang CL, Huyck M, DeLisi C. VisANT 3.5: multi-scale network visualization, analysis and inference based on the gene ontology. Nucleic Acids Res. 2009;37:115121.

36. Chen J, Wang M, Kong Y, Ma H, Zou S. Comparison of the novel compounds creatine and pyruvate on lipid and protein metabolism in broiler chickens. Animal. 2011;5:1082-

37. Chang SC, Lee I, Ting H, Chang YJ. Yang NC. Parapyruvate, an Impurity in Pyruvate Supplements, Induces Senescence in Human Fibroblastic Hs68 Cells via Inhibition of the a-Ketoglutarate Dehydrogenase Complex. J Agric Food Chem. 2018;66:7504-7513.

38. Zhao M, Gong D, Gao T, Zhang L, Li J, Lv PA, Gao F. In Ovo Feeding of Creatine Pyruvate Increases the Glycolysis Pathway, Glucose Transporter Gene Expression, and AMPK Phosphorylation in Breast Muscle of Neonatal Broilers. J Agric Food Chem. 2018;66:7684-7691. 
39. Yu D, Luo C, Fu W, Li Z. New thermal-responsive polymers based on alanine and (meth) acryl amides. Polym Chem. 2014;5:4561-4568.

40. Lambert IH, Kristensen DM, Holm JB, Mortensen O. H. Physiological role of taurine-from organism to organelle. Acta Physiol. 2015;213:191-

41. De Luca A, Pierno S, Camerino DC. Taurine: the appeal of a safe amino acid for skeletal muscle disorders. J Transl Med. 2015;13:243.

42. Schaffer S, Kim HW. Effects and mechanisms of taurine as a therapeutic agent. Biomol Ther.2018; 26:225-

43. Seidel U, Huebbe P, Rimbach G. Taurine: A regulator of cellular redox-homeostasis and skeletal muscle function. Mol Nutr Food Res. 2018; No:e1800569.

44. Ribeiro RA, Bonfleur ML, Batista TM, Borck PC, Carneiro EM. Regulation of glucose and lipid metabolism by the pancreatic and extra-pancreatic actions of taurine. Amino Acids. 2018;50:1511-

45. Li XW, Gao HY, Liu J. The role of taurine in improving neural stem cells proliferation and differentiation. Nutr Neurosci. 2017;20:409-

46. Rasmussen DD, Ishizuka B, Quigley ME, Yen SSC. Effects of Tyrosine and Tryptophan Ingestion on Plasma Catecholamine and 3,4-Dihydroxyphenylacetic Acid Concentrations. J Clin Endocrinol Metab.1983;57:760-763.

47. Deijen JB, Orlebeke JF. Effect of Tyrosine on Cognitive Function and Blood Pressure under Stress. Brain Res Bull. 1994;33:319-323.

48. Clark KD. Altered Tyrosine Metabolism and Melanization Complex Formation Underlie the Developmental Regulation of Melanization in Manduca Sexta. Insect Biochem Mol Biol. 2015;58;66-75.

49. Held PK. Disorders of Tyrosine Mol Genet Metab. 2006;88:103-106.

50. Felger JC, Li L, Marvar PJ, Woolwine BJ, Harrison DG, Raison CL, Miller AH. Tyrosine Metabolism during Interferon- alpha Administration: Association with Fatigue and CSF Dopamine Concentrations. Brain Behav Immun. 2013;31:153-160.

51. Ramos AC, Ferreira GK, Carvalho-Silva M, Furlanetto CB, Gonçalves CL, Ferreira GC, Streck E L. Acute Administration of I-Tyrosine Alters Energetic Metabolism of Hippocamp us and Striatum of Infant Rats. Int J Dev Neurosci. 2013;31:303-307.

52. van Loon LJC, Saris WHM, Verhagen $\mathrm{H}$, Wagenmakers AJ. Plasma insulin responses after ingestion of different amino acid or protein mixtures with carbohydrate. Am J Clin Nutr. 2000;72: 96-105.

53. Masaki T, Yoshimatsu H, Sakata T. Expression of rat uncoupling protein family mRNA levels by chronic treatment with thyroid hormone. Int J Obes Relat Metab Disord. 2000;24:162-164.

\section{Tables}

Table 1 Composition and nutrient levels of the complete diets for broilers 


\begin{tabular}{|c|c|c|}
\hline Item & 1 to 3 weeks & 4 to 6 weeks \\
\hline \multicolumn{3}{|l|}{ Ingredients (\%) } \\
\hline Corn & 53.36 & 56.51 \\
\hline Soybean meal & 38.50 & 35.52 \\
\hline Soybean oil & 4.10 & 4.50 \\
\hline $\mathrm{NaCl}$ & 0.30 & 0.30 \\
\hline Limestone & 1.15 & 1.00 \\
\hline $\mathrm{CaHPO}_{4}$ & 2.01 & 1.78 \\
\hline DL-Met & 0.22 & 0.11 \\
\hline Premix $^{1 \square}$ & $0.36^{1}$ & $0.28^{2}$ \\
\hline Total & 100.00 & 100.00 \\
\hline \multicolumn{3}{|c|}{ Nutrient levels $(\%)^{2)}$} \\
\hline $\mathrm{ME} /\left(\mathrm{MJ} \mathrm{kg}^{-1}\right)$ & 12.46 & 12.73 \\
\hline $\mathrm{CP}$ & 21.44 & 20.07 \\
\hline $\mathrm{Ca}$ & 1.00 & 0.90 \\
\hline AP & 0.45 & 0.40 \\
\hline Lys & 1.17 & 1.00 \\
\hline Met & 0.56 & 0.42 \\
\hline Met+Cys & 0.91 & 0.78 \\
\hline
\end{tabular}

${ }^{1)}$ The premix was given for 1-3 wk provided the following nutrients per kilogram of diet: Vitamin A,12,500 IU; Vitamin $\mathrm{D}_{3}$, 3,750 IU; Vitamin E, 16 IU; Vitamin $\mathrm{K}_{3}, 2.0$ mg; Vitamin $\mathrm{B}_{1}$, $2.5 \mathrm{mg}$; Vitamin $\mathrm{B}_{2}, 8$ mg; Vitamin $\mathrm{B}_{6}, 2.5 \mathrm{mg}$; Vitamin $\mathrm{B}_{12}, 0.015$ mg, Panthoenic acid calcium, 12.5 mg; Nicotinic acid, $32.5 \mathrm{mg}$; Folic acid, $1.25 \mathrm{mg}$; Biotin, $0.125 \mathrm{mg}$; Choline, $700 \mathrm{mg}$; $\mathrm{Zn}\left(\mathrm{ZnSO}_{4} \cdot 7 \mathrm{H}_{2} \mathrm{O}\right), 60 \mathrm{mg} ; \mathrm{Fe}\left(\mathrm{FeSO} \cdot \cdot 7 \mathrm{H}_{2} \mathrm{O}\right), 80 \mathrm{mg} ; \mathrm{Cu}$ $\left(\mathrm{CuSO}_{4} \cdot 5 \mathrm{H}_{2} \mathrm{O}\right), 8 \mathrm{mg} ; \mathrm{Mn}\left(\mathrm{MnSO}_{4} \cdot \mathrm{H}_{2} \mathrm{O}\right), 110 \mathrm{mg}$; I (KI), $0.35 \mathrm{mg} ; \mathrm{Se}\left(\mathrm{Na}_{2} \mathrm{SeO}_{3}\right), 0.15 \mathrm{mg}$. The premix was given for 4-6 wk provided the following nutrients per kilogram of diet: Vitamin A, 10,000 IU; Vitamin $\mathrm{D}_{3}, 3,400 \mathrm{IU}$; Vitamin E,16 IU; Vitamin $\mathrm{K}_{3}, 2.0$ mg; Vitamin $\mathrm{B}_{1}$, 2.0 mg; Vitamin $\mathrm{B}_{2}$, $6.4 \mathrm{mg}$; Vitamin $\mathrm{B}_{6}, 2.0 \mathrm{mg}$; Vitamin $\mathrm{B}_{12}, 0.012 \mathrm{mg}$; pantothenic acid calcium, $10 \mathrm{mg}$; nicotinic acid, $26 \mathrm{mg}$; folic acid, $1 \mathrm{mg}$; biotin, $0.1 \mathrm{mg}$; choline, 
$500 \mathrm{mg} ; \mathrm{Zn}\left(\mathrm{ZnSO}_{4} \cdot 7 \mathrm{H}_{2} \mathrm{O}\right), 40 \mathrm{mg} ; \mathrm{Fe}\left(\mathrm{FeSO}_{4} \cdot 7 \mathrm{H}_{2} \mathrm{O}\right), 80 \mathrm{mg} ; \mathrm{Cu}\left(\mathrm{CuSO}_{4} \cdot 5 \mathrm{H}_{2} \mathrm{O}\right), 8 \mathrm{mg} ; \mathrm{Mn}\left(\mathrm{MnSO}_{4} \cdot \mathrm{H}_{2} \mathrm{O}\right), 80 \mathrm{mg} ; \mathrm{I}(\mathrm{KI}), 0.35 \mathrm{mg} ; \mathrm{Se}\left(\mathrm{Na}_{2} \mathrm{SeO}\right)_{3}, 0.15$ mg.

\footnotetext{
${ }^{2)}$ metabolizable energy was calculated, whereas the others were measured.
}

Table 2 Real-time PCR primer sequences

\begin{tabular}{cccc}
\hline Gene & Primer & RT-PCR primers: ${\text { 5 } \rightarrow 3^{\prime}}^{2}$ & PCR \\
& & & product size \\
\hline Av UCP & Gallus-avUCP-F & 5-ATCGGGCTCTACGACTCTGT-3 & $327 \mathrm{bp}$ \\
& Gallus-avUCP-R & 5-TGTGTCCTTGATGAGGTCGT-3 & \\
& & & $130 \mathrm{bp}$ \\
GAPDH & Gallus-GAPDH-F & 5-AACTTTGGCATTGTGGAGGG-3 & \\
& & & \\
\hline
\end{tabular}

Table 3 PLS-DA evaluation parameters of the model

\begin{tabular}{lccccccc}
\hline Detection mode & \multicolumn{3}{c}{ HILIC } & \multicolumn{3}{c}{ HSS } & T3 \\
\cline { 2 - 8 } & Number of PC & $\begin{array}{c}\text { R2 } \\
\square \text { cum } \square \\
\square \text { cum } \square\end{array}$ & $\begin{array}{c}\text { Q2 } \\
\square \text { cum } \square\end{array}$ & Number of PC & $\begin{array}{c}\text { R2 } \\
\square \text { cum } \square\end{array}$ & Q2 \\
$\square$ cum $\square$ \\
Positive-ion mode & 2 & 0.96027 & 0.56395 & 2 & 0.8857 & 0.1632 \\
Negative-ion mode & 2 & 0.93487 & 0.45529 & 2 & 0.95459 & 0.27842 \\
\hline
\end{tabular}

R2:fitness ability of the models;Q2 2 prediction ability of the models;R2 and Q2 (cum)>50\% shows that the mode is useful; if R2 and the Q2 (cum) $>90 \%$, the mode is excellent.

Table 4 Samples of HILIC cation and anion G1-G3-G5 group of chicken manure to identify differences in metabolites 


\begin{tabular}{|c|c|c|c|c|c|c|c|}
\hline $\begin{array}{l}\text { Ionization } \\
\text { Mode } \\
\text { (HILIC) }\end{array}$ & adduct & VIP & $P$ vaule & $\mathrm{m} / \mathrm{z}$ & rts & Formula & metabolite \\
\hline$\overline{\operatorname{ESI}(+)}$ & $(\mathrm{M}+\mathrm{NH} 4)+$ & 1.6567 & 0.024099 & 533.3251 & 107.138 & $\mathrm{C}_{26} \mathrm{H}_{45} \mathrm{NO}_{7} \mathrm{~S}$ & Taurocholate \\
\hline $\mathrm{ESI}(+)$ & $(\mathrm{M}+\mathrm{CH} 3 \mathrm{COO}+2 \mathrm{H})+$ & 1.1165 & 0.025783 & 251.1387 & 158.951 & $\mathrm{C}_{6} \mathrm{H}_{14} \mathrm{~N}_{4} \mathrm{O}_{3}$ & $\mathrm{~N}$-(omega)-Hydroxyarginine \\
\hline $\mathrm{ESI}(+)$ & $(\mathrm{M}+\mathrm{H})+$ & 1.8343 & 0.011604 & 130.0496 & 448.408 & $\mathrm{C}_{5} \mathrm{H}_{7} \mathrm{NO}_{3}$ & L-Pyroglutamic acid \\
\hline $\mathrm{ESI}(+)$ & $(\mathrm{M}+\mathrm{H})+$ & 2.8862 & 0.016132 & 132.0663 & 385.740 & $\mathrm{C}_{5} \mathrm{H}_{9} \mathrm{NO}_{3}$ & Hydroxyproline \\
\hline $\operatorname{ESI}(+)$ & $(\mathrm{M}+\mathrm{H})+$ & 1.0334 & 0.016313 & 112.0869 & 107.218 & $\mathrm{C}_{5} \mathrm{H}_{9} \mathrm{~N}_{3}$ & Histamine \\
\hline $\mathrm{ESI}(+)$ & $(\mathrm{M}+\mathrm{H})+$ & 2.0389 & 0.003919 & 147.076 & 448.394 & $\mathrm{C}_{5} \mathrm{H}_{10} \mathrm{~N}_{2} \mathrm{O}_{3}$ & L-Glutamine \\
\hline $\mathrm{ESI}(+)$ & $(\mathrm{M}+\mathrm{H})+$ & 2.137 & 0.027125 & 201.9836 & 302.696 & $\mathrm{C}_{3} \mathrm{H}_{7} \mathrm{NO}_{5} \mathrm{~S}_{2}$ & Cysteine-S-sulfate \\
\hline $\operatorname{ESI}(+)$ & $(\mathrm{M}+\mathrm{H}-\mathrm{H} 2 \mathrm{O})+$ & 1.8167 & 0.014495 & 241.0927 & 90.538 & & Acadesine (Drug) \\
\hline $\operatorname{ESI}(+)$ & $(\mathrm{M}+\mathrm{H})+$ & 2.0528 & 0.008267 & 146.0928 & 410.597 & $\mathrm{C}_{5} \mathrm{H}_{11} \mathrm{~N}_{3} \mathrm{O}_{2}$ & 4-Guanidinobutyric acid \\
\hline $\operatorname{ESI}(+)$ & $(\mathrm{M}+\mathrm{H})+$ & 1.0994 & 0.002954 & 126.1025 & 383.346 & & l-Methylhistamine \\
\hline ESI(-) & (M-H)- & 3.0329 & 0.001232 & 111.0203 & 88.403 & $\mathrm{C}_{4} \mathrm{H}_{4} \mathrm{~N}_{2} \mathrm{O}_{2}$ & Uracil \\
\hline ESI(-) & $(\mathrm{M}-\mathrm{H})-$ & 1.6072 & 0.011230 & 514.2802 & 103.059 & $\mathrm{C}_{26} \mathrm{H}_{45} \mathrm{NO}_{7} \mathrm{~S}$ & Taurocholate \\
\hline ESI(-) & $(\mathrm{M}-\mathrm{H})-$ & 2.1443 & 0.040660 & 117.0204 & 505.952 & $\mathrm{C}_{4} \mathrm{H}_{6} \mathrm{O}_{4}$ & Succinate \\
\hline ESI(-) & $(\mathrm{M}+\mathrm{CH} 3 \mathrm{COO})-$ & 1.8129 & 0.003737 & 725.2303 & 746.889 & $\mathrm{C}_{24} \mathrm{H}_{42} \mathrm{O}_{21}$ & Stachyose \\
\hline ESI(-) & $(\mathrm{M}-\mathrm{H})-$ & 1.1399 & 0.031148 & 115.0034 & 160.740 & $\mathrm{C}_{4} \mathrm{H}_{4} \mathrm{O}_{4}$ & Maleic acid \\
\hline ESI(-) & $(\mathrm{M}-\mathrm{H})-$ & 2.3313 & 0.002030 & 128.0351 & 386.61 & $\mathrm{C}_{5} \mathrm{H}_{7} \mathrm{NO}_{3}$ & L-Pyroglutamic acid \\
\hline ESI(-) & $(\mathrm{M}-\mathrm{H})-$ & 2.4013 & 0.045091 & 181.0500 & 161.396 & $\mathrm{C}_{9} \mathrm{H}_{10} \mathrm{O}_{4}$ & Hydroxyphenyllactic acid \\
\hline ESI(-) & $(\mathrm{M}-\mathrm{H})-$ & 2.2755 & 0.033835 & 193.0355 & 497.042 & $\mathrm{C}_{6} \mathrm{H}_{10} \mathrm{O}_{7}$ & D-galacturonic acid \\
\hline ESI(-) & $(\mathrm{M}-\mathrm{H})-$ & 2.0934 & 0.025000 & 199.9690 & 300.059 & $\mathrm{C}_{3} \mathrm{H}_{7} \mathrm{NO}_{5} \mathrm{~S}_{2}$ & Cysteine-S-sulfate \\
\hline ESI(-) & $(\mathrm{M}-\mathrm{H})-$ & 1.0862 & 0.030828 & 145.0503 & 489.616 & $\mathrm{C}_{6} \mathrm{H}_{10} \mathrm{O}_{4}$ & Adipic acid \\
\hline ESI(-) & $(\mathrm{M}-\mathrm{H})-$ & 1.9144 & 0.046224 & 163.0400 & 107.911 & $\mathrm{C}_{9} \mathrm{H}_{8} \mathrm{O}_{3}$ & 4-Hydroxycinnamic acid \\
\hline ESI(-) & $(\mathrm{M}-\mathrm{H})-$ & 3.1972 & 0.01728 & 175.0610 & 394.802 & $\mathrm{C}_{7} \mathrm{H}_{12} \mathrm{O}_{5}$ & 2-Isopropylmalic acid \\
\hline
\end{tabular}

Table 5 Samples of HSST3 cation and anion G1-G3-G5 group of chicken manure to identify differences in metabolites

\begin{tabular}{cccccccc}
\hline $\begin{array}{c}\text { Ionization } \\
\text { Mode } \\
(\mathrm{HSST})\end{array}$ & adduct & VIP & P vaule & $\mathrm{m} / \mathrm{z}$ & $\mathrm{rts}$ & Formula & metabolite \\
\hline ESI(+) & $(\mathrm{M}+\mathrm{H})+$ & 2.885 & 0.0459731 & 153.0407 & 140.121 & $\mathrm{C}_{5} \mathrm{H}_{4} \mathrm{~N}_{4} \mathrm{O}_{2}$ & Xanthine \\
ESI(+) & $(\mathrm{M}+\mathrm{H})+$ & 1.159 & 0.0348263 & 516.3009 & 451.884 & $\mathrm{C}_{26} \mathrm{H}_{45} \mathrm{NO}_{7} \mathrm{~S}$ & Taurocholate \\
ESI(+) & $(\mathrm{M}+\mathrm{H})+$ & 2.303 & 0.00147405 & 281.1152 & 276.2585 & $\mathrm{C}_{13} \mathrm{H}_{16} \mathrm{~N}_{2} \mathrm{O}_{5}$ & L-Aspartyl-L-phenylalanine \\
ESI(+) & $(\mathrm{M}+\mathrm{H})+$ & 2.722 & 0.00231868 & 166.0538 & 52.196 & $\mathrm{C}_{5} \mathrm{H}_{11} \mathrm{NO}_{3} \mathrm{~S}$ & DL-Methionine sulfoxide \\
ESI(+) & $(\mathrm{M}+\mathrm{H}-\mathrm{H} 2 \mathrm{O})+$ & 2.165 & 0.0375587 & 241.0942 & 224.479 & & Acadesine (Drug) \\
ESI(-) & $(\mathrm{M}-\mathrm{H})-$ & 3.1789 & 0.004477 & 111.0188 & 71.9575 & $\mathrm{C}_{4} \mathrm{H}_{4} \mathrm{~N}_{2} \mathrm{O}_{2}$ & Uracil \\
ESI(-) & $(\mathrm{M}-\mathrm{H})-$ & 2.6688 & 0.001702 & 125.0343 & 202.795 & $\mathrm{C}_{5} \mathrm{H}_{6} \mathrm{~N}_{2} \mathrm{O}_{2}$ & Thymine \\
ESI(-) & $(\mathrm{M}-\mathrm{H})-$ & 2.4173 & 0.006158 & 514.2805 & 359.21 & $\mathrm{C}_{26} \mathrm{H}_{45} \mathrm{NO}_{7} \mathrm{~S}$ & Taurocholate \\
ESI(-) & $(\mathrm{M}-\mathrm{H})-$ & 1.821 & 0.048278 & 212.0004 & 243.728 & $\mathrm{C}_{14} \mathrm{H}_{17} \mathrm{NO}_{6}$ & Indoxylsulfate \\
ESI(-) & $(\mathrm{M}-\mathrm{H})-$ & 1.6296 & 0.041899 & 179.0334 & 204.091 & $\mathrm{C}_{9} \mathrm{H}_{8} \mathrm{O}_{4}$ & Caffeic Acid \\
ESI(-) & $(\mathrm{M}-\mathrm{H})-$ & 3.1267 & 0.001074 & 121.0283 & 216.653 & $\mathrm{C}_{7} \mathrm{H}_{6} \mathrm{O}_{2}$ & Benzoic acid \\
ESI(-) & $(\mathrm{M}-\mathrm{H} 2 \mathrm{O}-\mathrm{H})-$ & 1.3353 & 0.028934 & 241.011 & 45.323 & $\mathrm{C}_{6} \mathrm{H}_{13} \mathrm{O}_{9} \mathrm{P}$ & alpha-D-Glucose 1-phosphate \\
ESI(-) & $(\mathrm{M}-\mathrm{H})-$ & 2.6852 & 0.007368 & 134.0457 & 233.806 & $\mathrm{C}_{5} \mathrm{H}_{5} \mathrm{~N}_{5}$ & Adenine \\
ESI(-) & $(\mathrm{M}-\mathrm{H})-$ & 3.5747 & 0.003354 & 109.0283 & 306.3185 & $\mathrm{C}_{6} \mathrm{H}_{6} \mathrm{O}_{2}$ & 1,4-Dihydroxybenzene \\
\hline
\end{tabular}

Table 6 Affected metabolic pathways including more than $\geq 3$ metabolites (KEGG database matched results) 


\begin{tabular}{|c|c|c|}
\hline ID & $\begin{array}{l}\text { Metabolic pathway } \\
\text { name }\end{array}$ & Cpd \\
\hline map00120 & $\begin{array}{l}\text { Primary bile acid } \\
\text { biosynthesis (9) }\end{array}$ & $\begin{array}{c}\text { Taurodeoxycholic acid, Taurochenodeoxycholate, Taurocholate, Taurochenodeoxycholate, Taurocholate, } \\
\text { Cholic acid, Taurocholate, Taurochenodeoxycholate, Cholic acid }\end{array}$ \\
\hline map00430 & $\begin{array}{l}\text { Taurine and } \\
\text { hypotaurine } \\
\text { metabolism(4) }\end{array}$ & Taurocholate, Taurocholate, Taurocholate, Taurocholate, \\
\hline map00360 & $\begin{array}{l}\text { Phenylalanine } \\
\text { metabolism(6) }\end{array}$ & $\begin{array}{c}\text { Succinate, 4-Hydroxycinnamic acid, L-Phenylalanine, Benzoic acid, 3-Phenylpropanoic acid, 2- } \\
\text { Hydroxyphenylacetic acid }\end{array}$ \\
\hline map00340 & $\begin{array}{c}\text { Histidine } \\
\text { metabolism(4) }\end{array}$ & L-Carnosine, Histamine, 3-Methylhistidine, 1-Methylhistamine \\
\hline map00350 & $\begin{array}{c}\text { Tyrosine } \\
\text { metabolism(5) }\end{array}$ & Succinate, Maleic acid, 4-Hydroxycinnamic acid, Tyramine, 1,4-Dihydroxybenzene \\
\hline map00620 & $\begin{array}{c}\text { Pyruvate } \\
\text { metabolism(3) }\end{array}$ & Succinate, Pyruvaldehyde, 2-Isopropylmalic acid \\
\hline map00410 & $\begin{array}{l}\text { beta-Alanine } \\
\text { metabolism(3) }\end{array}$ & Uracil, L-Carnosine, Uracil \\
\hline map00270 & $\begin{array}{l}\text { Cysteine and } \\
\text { methionine } \\
\text { metabolism(4) }\end{array}$ & L-Methionine, Cysteine-S-sulfate, Cysteine-S-sulfate, DL-Methionine sulfoxide \\
\hline map00240 & $\begin{array}{c}\text { Pyrimidine } \\
\text { metabolism(4) }\end{array}$ & L-Glutamine, Uracil, Uracil, Thymine \\
\hline map00330 & $\begin{array}{l}\text { Arginine and proline } \\
\text { metabolism(4) }\end{array}$ & N-(omega)-Hydroxyarginine, Hydroxyproline, 4-Guanidinobutyric acid, D-Proline \\
\hline map00052 & $\begin{array}{c}\text { Galactose } \\
\text { metabolism(3) }\end{array}$ & D-(+)-Melibiose, Stachyose, alpha-D-Glucose 1-phosphate \\
\hline map02010 & ABC transporters (5) & L-Glutamine, Hydroxyproline, D-(+)-Melibiose, D-galacturonic acid, L-Phenylalanine \\
\hline map00970 & $\begin{array}{l}\text { Aminoacyl-tRNA } \\
\text { biosynthesis(3) }\end{array}$ & L-Methionine, L-Glutamine, L-Phenylalanine \\
\hline
\end{tabular}

\section{Figures}


A

$$
P=0.02
$$

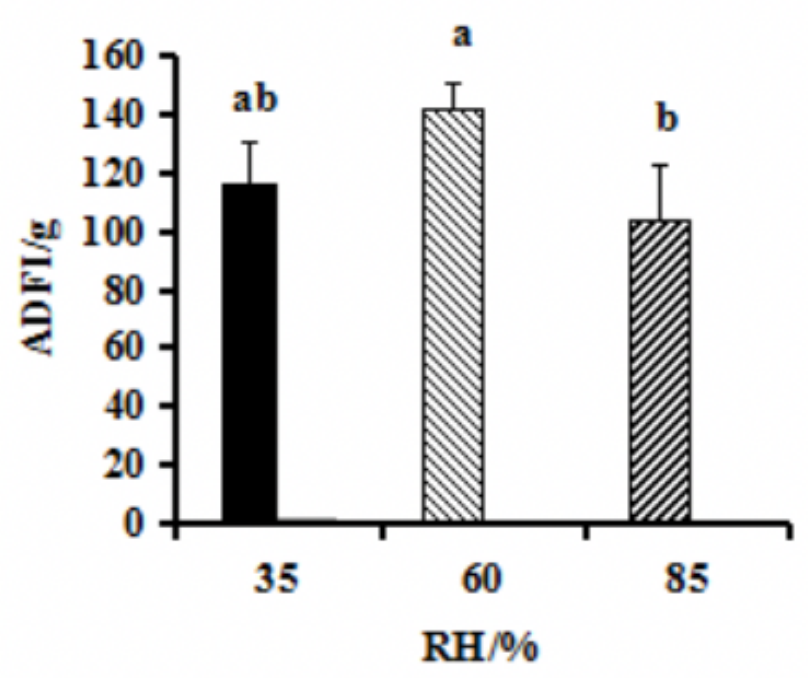

B

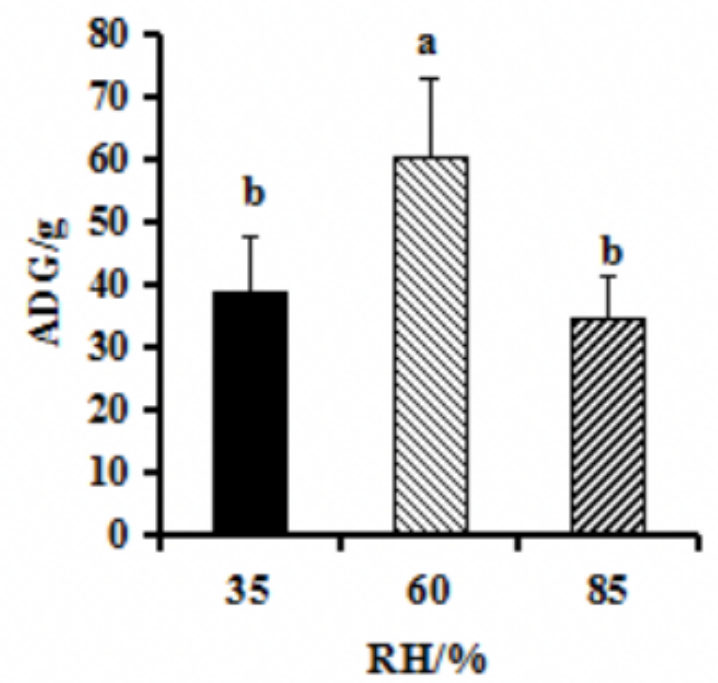

$\mathrm{C}$

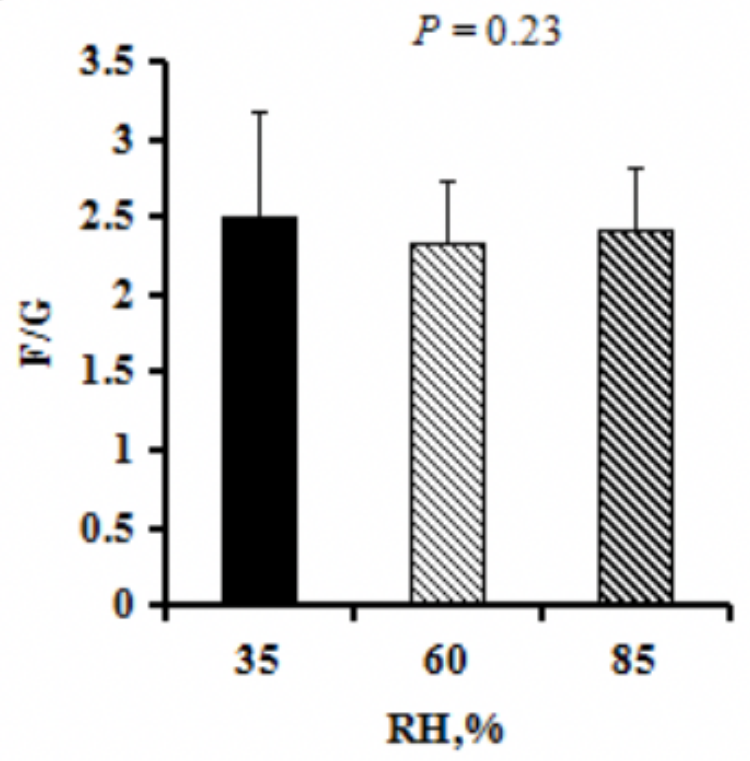

Figure 1

Effects of hot humid, mid or dry stress on growth performance of broilers: (A) average daily feed intake (ADFI), (B) average daily gain (ADG), (C) feed intake:gain ( $F / G)$. Different letters within the same time points indicate significant differences among the three treatments $(P<0.05)$. 

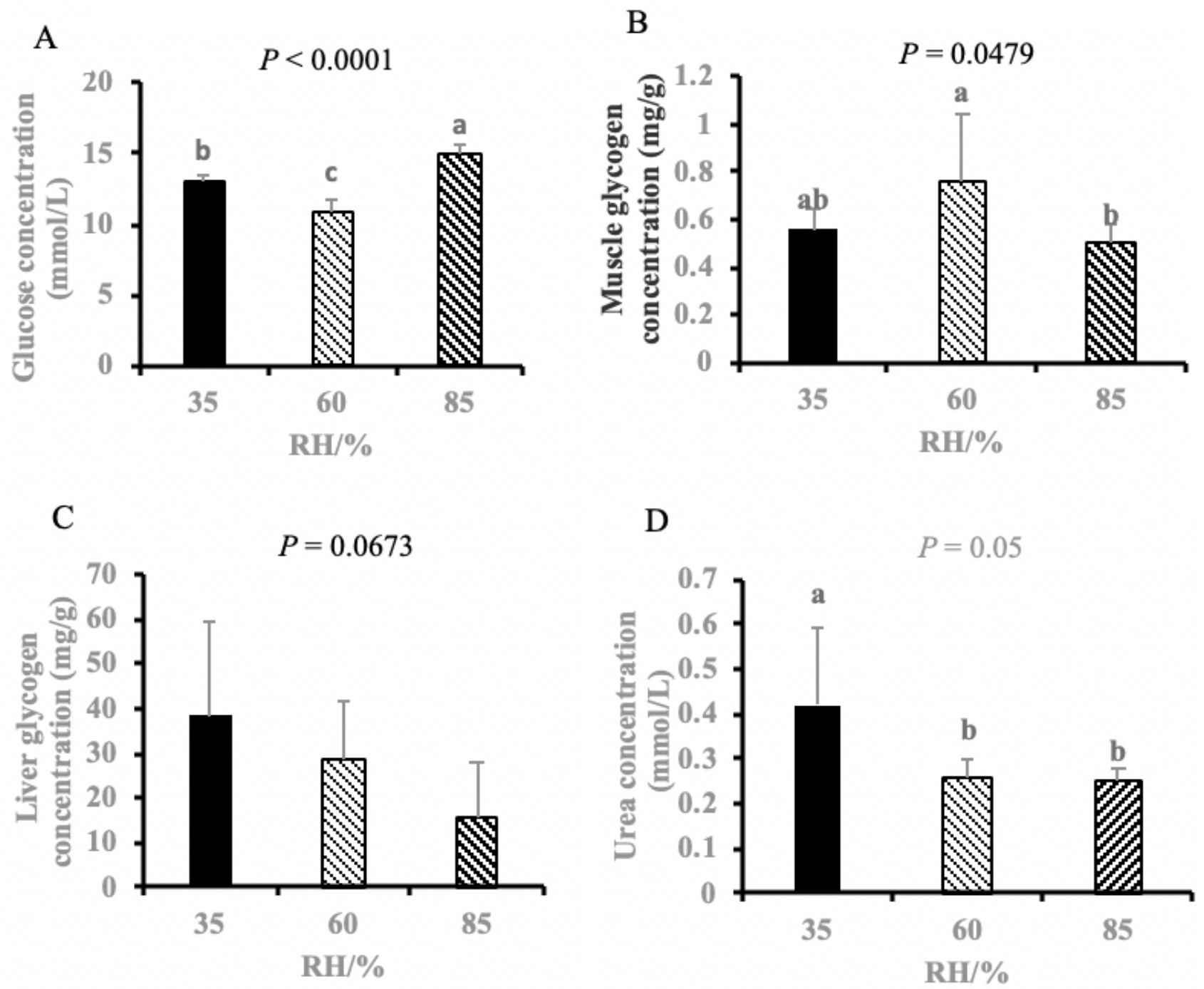

Figure 3

Effects of hot humid, mid or dry stress on the concentrations of blood glucose (A), muscle glycogen (B), liver glycogen (C), and blood urea (D) in broilers. Results are represented as the mean value \pm standard deviation of six sample birds per treatment $(n=6)$. Different letters within the same time points indicate significant differences among the three treatments $(P<0.05)$. 
A

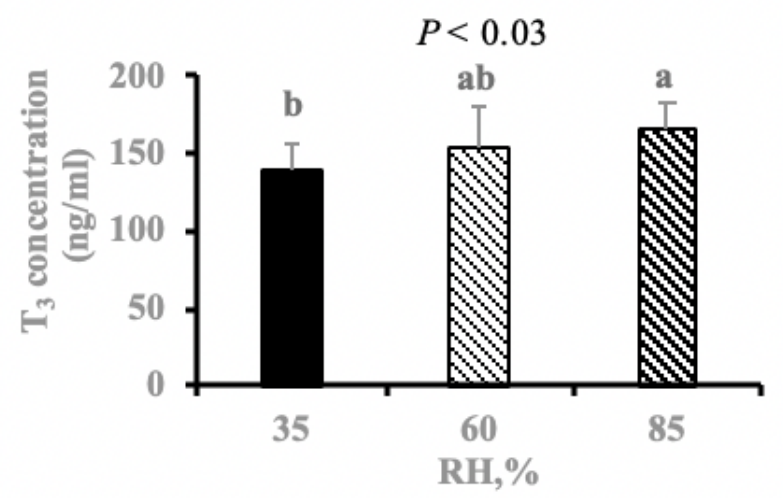

$\mathrm{C}$
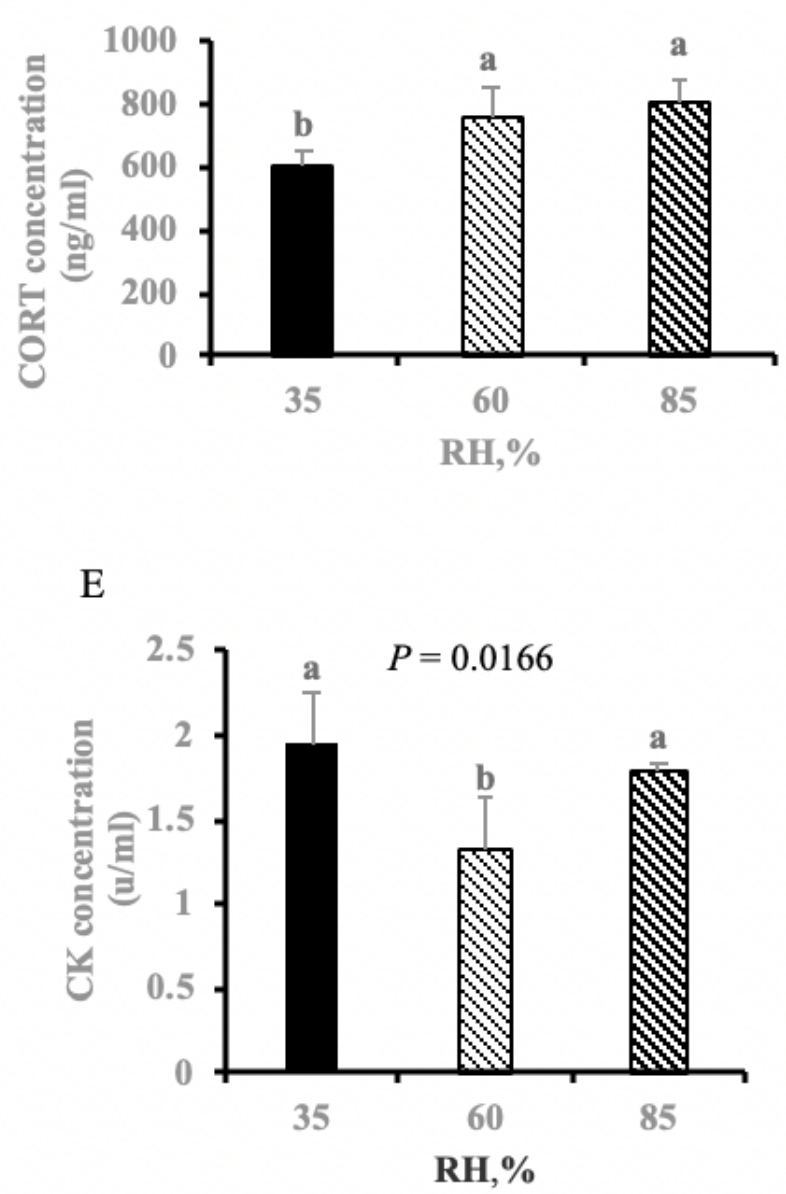

B

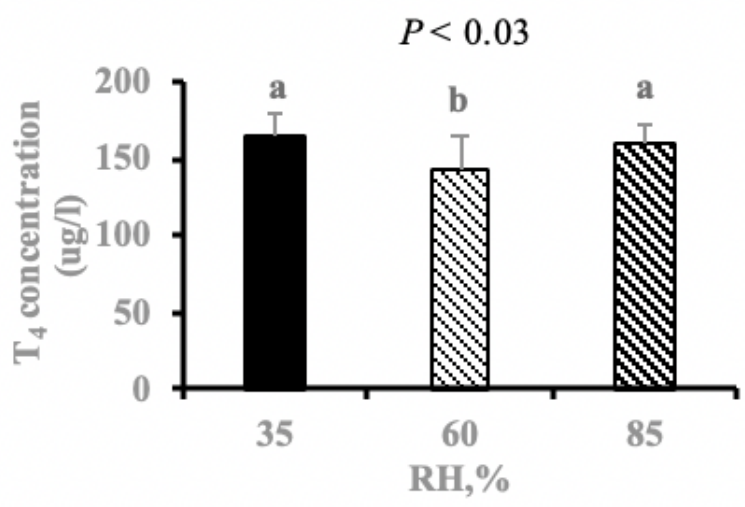

D
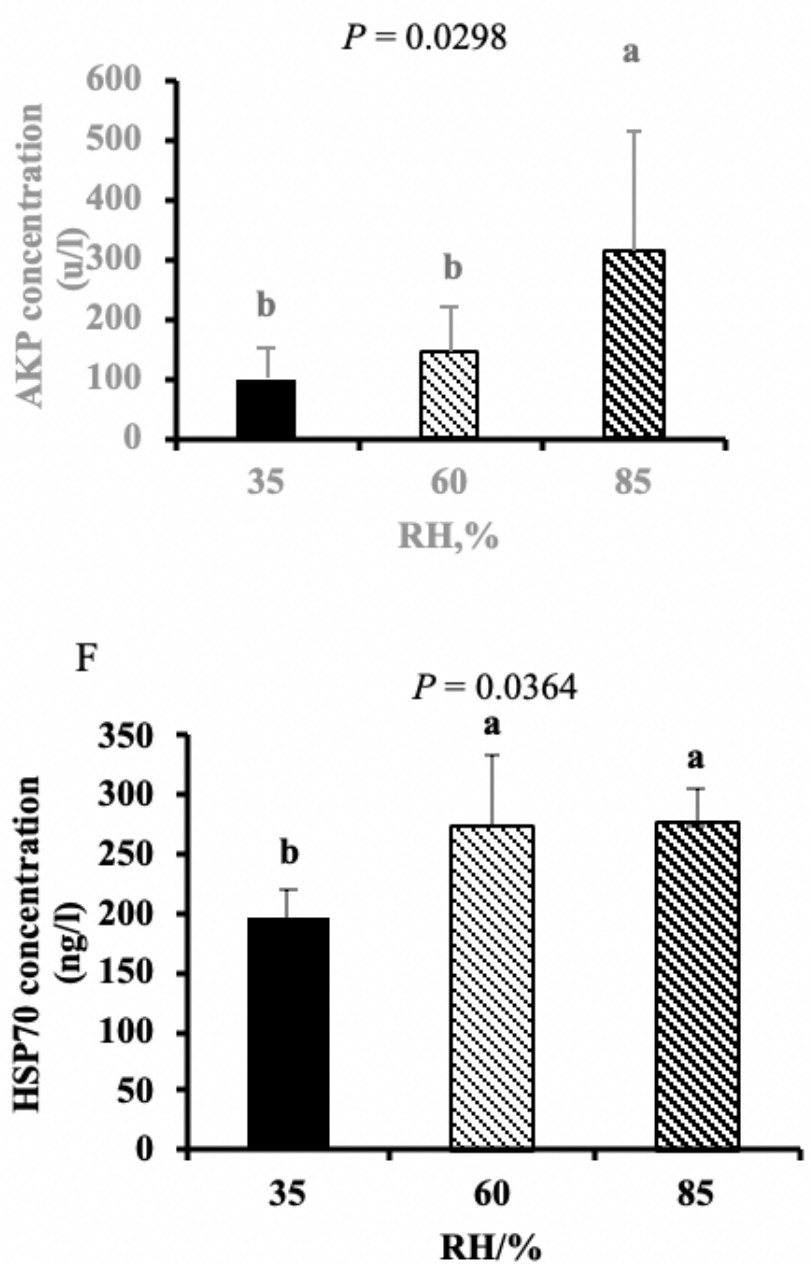

\section{Figure 5}

Effects of hot humid, mid or dry stress on the triiodothyronine T3 (A), thyroxine T4 (B), Corticosterone CORT (C), alkaline phosphatase AKP (D), Creatine Kinase CK (E) in blood and heat shock protein HSP 70 (F) of broilers. Results are represented as the mean value \pm standard deviation of six sample birds per treatment $(n=6)$. Different letters within the same time points indicate significant differences among the three treatments $(P<0.05)$. 

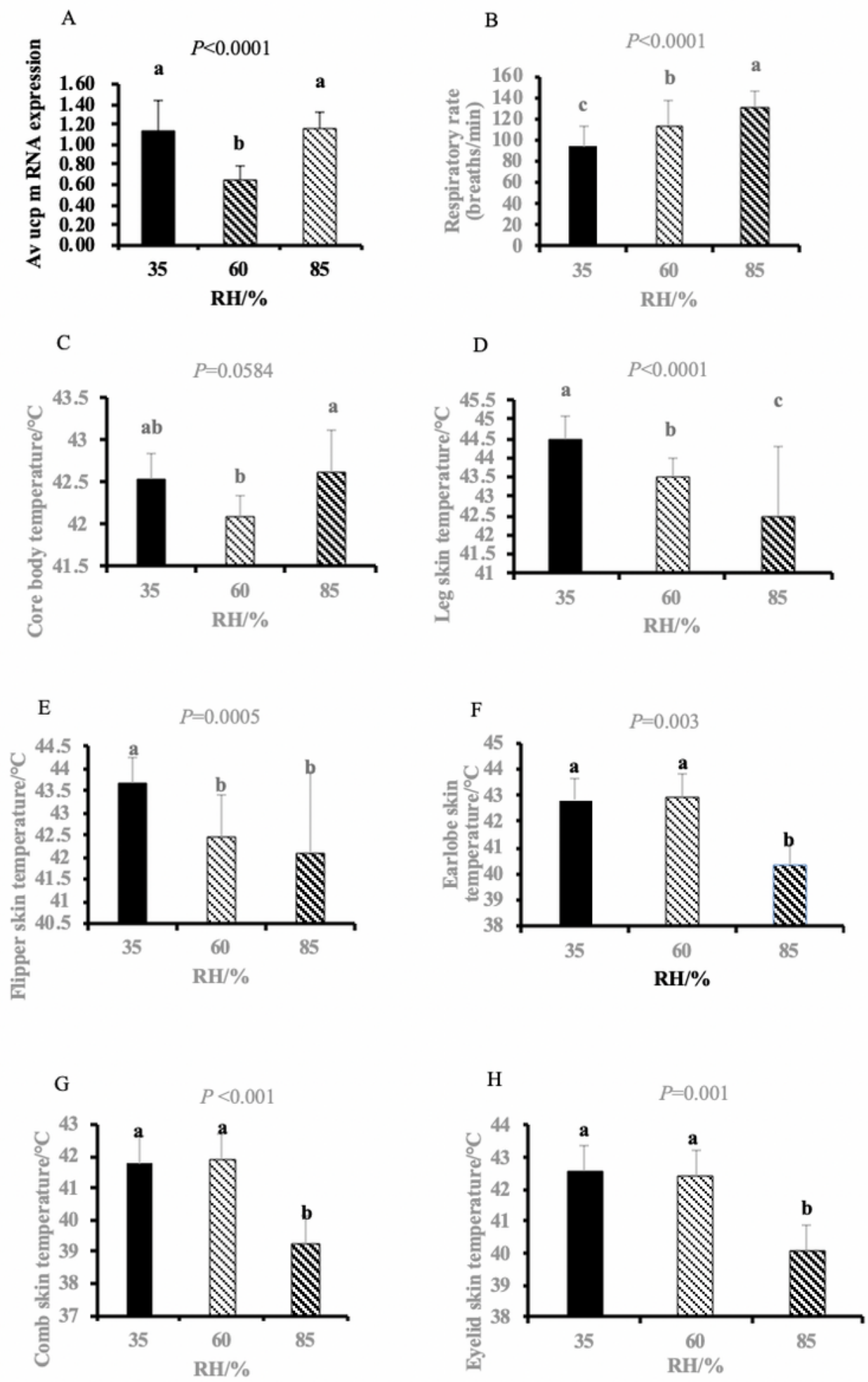

Figure 7

Effects of hot humid, mid or dry stress on the heat dissipation of broilers: (A) av ucp expression, (B) respiratory rate, $(C)$ core body temperature, (D) leg skin temperature, (E) flipper skin temperature, (F) earlobe skin temperature, $(\mathrm{G})$ comb skin temperature, $(\mathrm{H})$ eyelid skin temperature. Results are represented as the mean value \pm standard deviation of six sample birds per treatment $(n=6)$. Different letters within the same time points indicate significant differences among the three treatments $(P<0.05)$. 

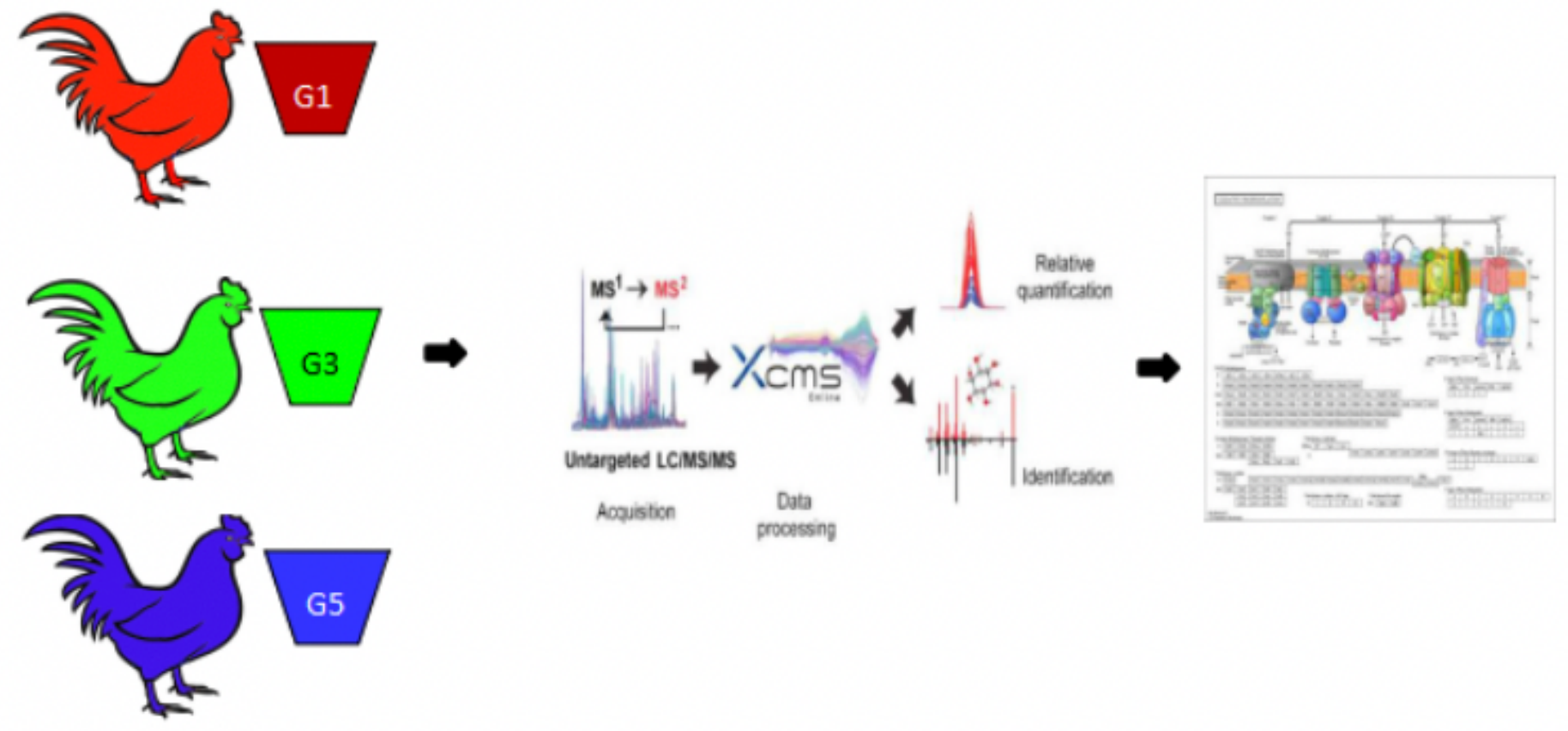

\section{Figure 9}

Schematic work flow of the experimental approach using autonomous untargeted metabolomics. Broilers (total 180 AA broilers: $\left.3{ }^{*} 6 * 10\right)$ were treated with changes in hot humid, mid or dry stress $(\mathrm{G} 1: 35 \% \mathrm{RH}$ at $32^{\circ} \mathrm{C}, \mathrm{G} 3: 60 \% \mathrm{RH}$ at $32^{\circ} \mathrm{C}, \mathrm{G} 5: 85 \% \mathrm{RH}$ at $32^{\circ} \mathrm{C}$ ). Fecal was harvested for metabolomics profiling using untargeted metabolomics that acquires MS and MS/MS data sequentially. Quantitative information is extracted from the MS data using XCMS Online and identification followed by pathway correlation. 
A

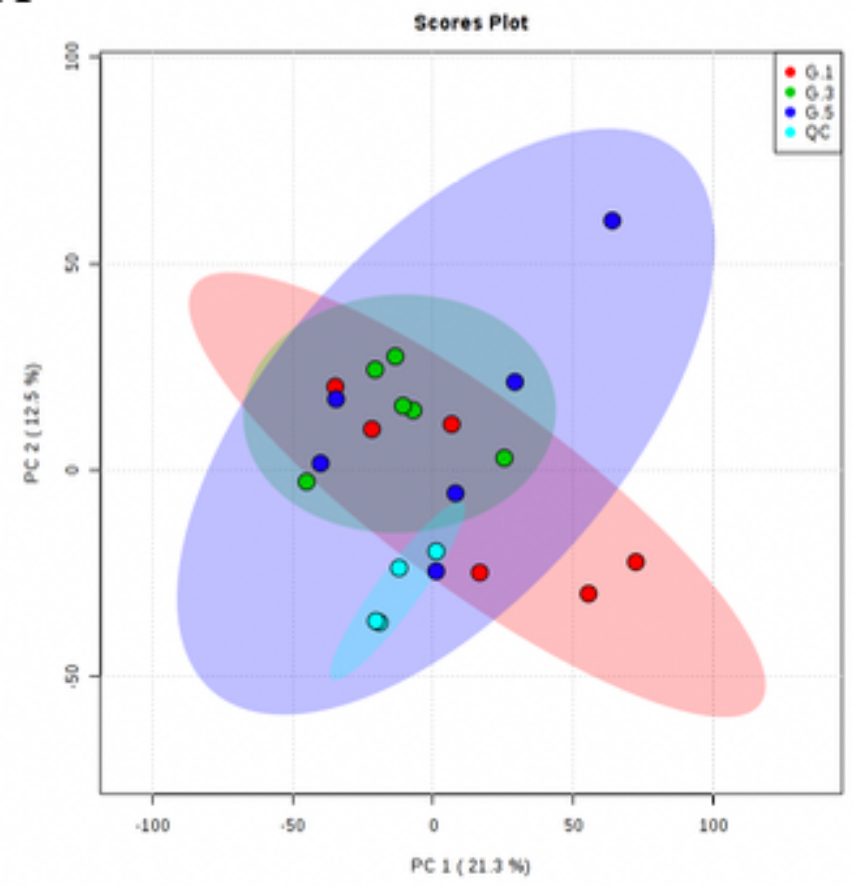

$\mathrm{C}$

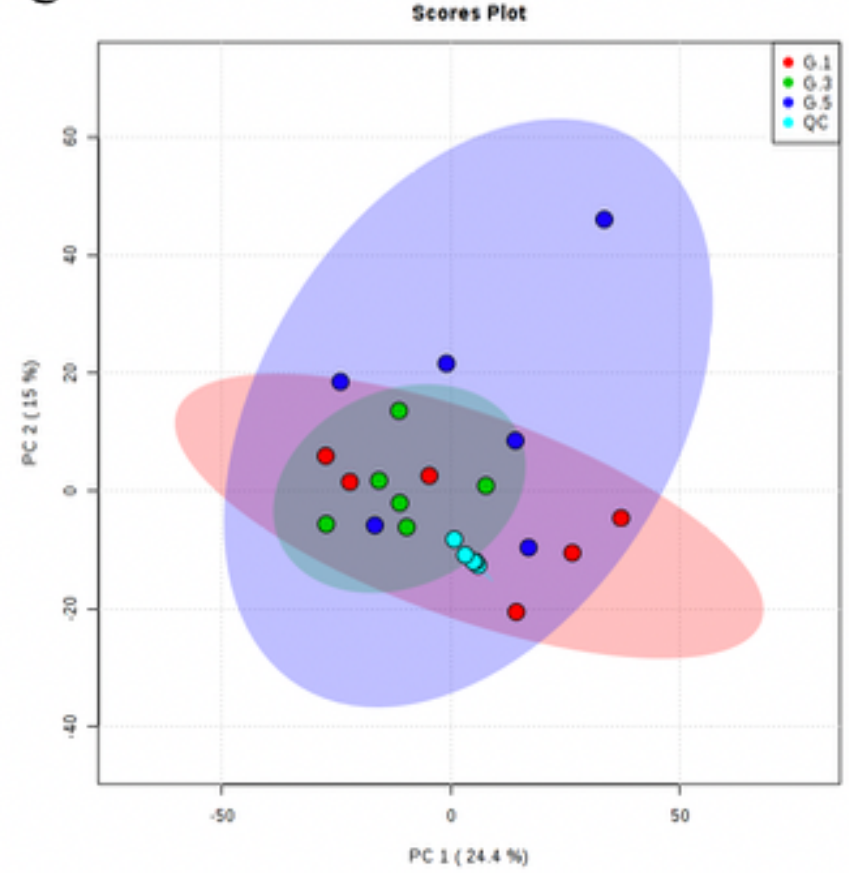

B

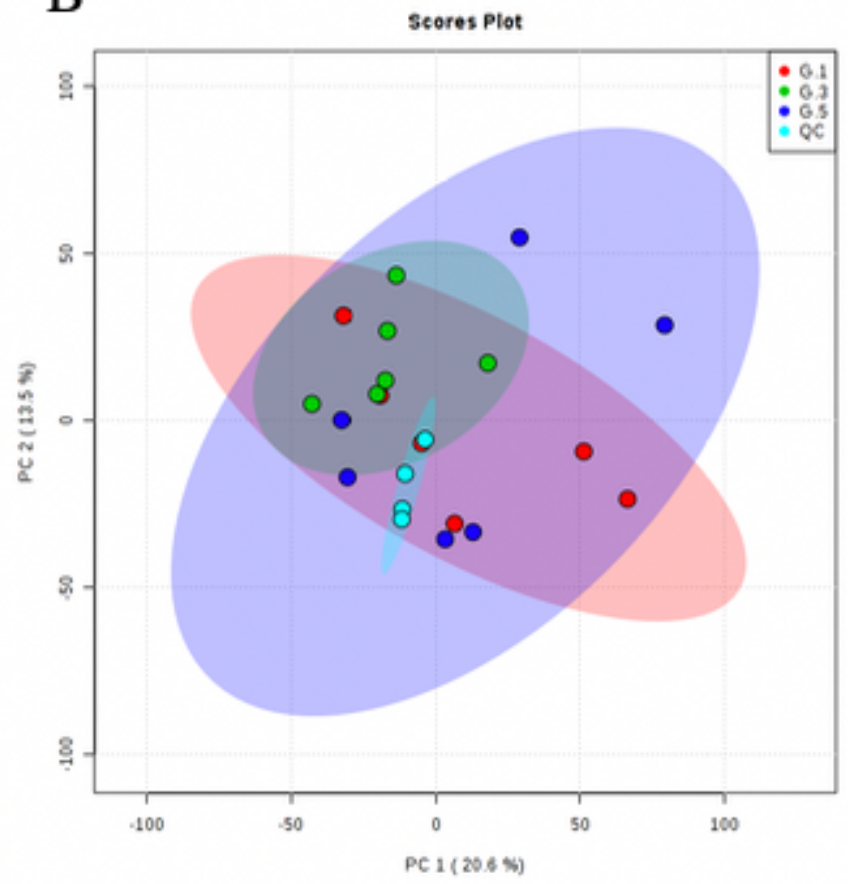

D

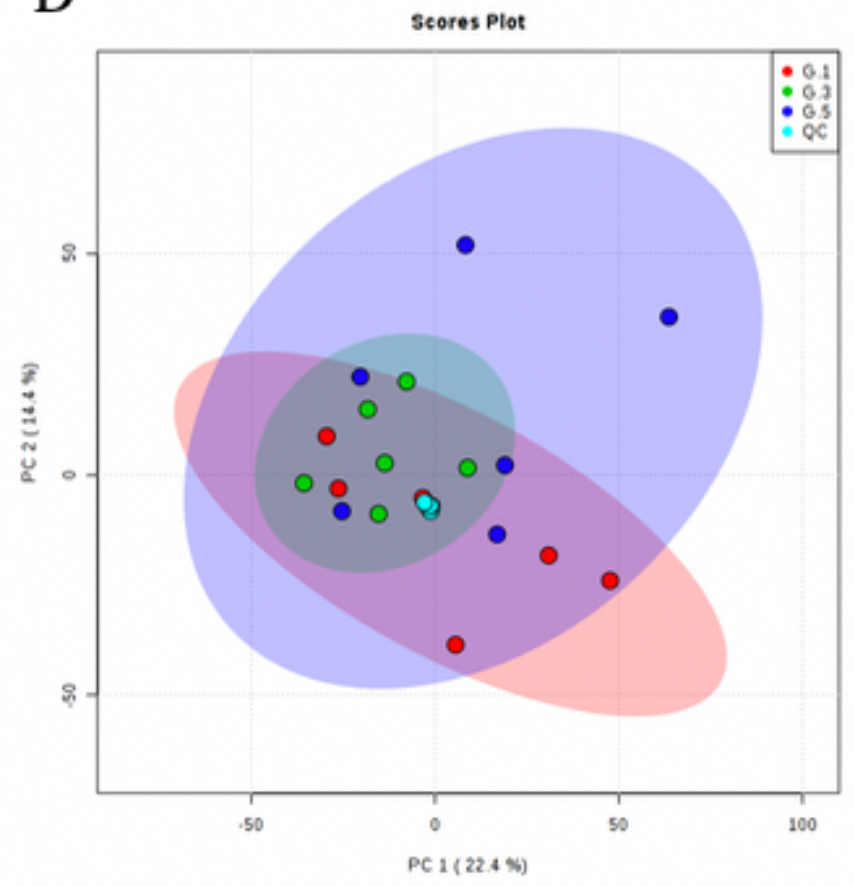

Figure 11

PCA score plots in ESI positive mode of HSST3(A), negative mode of HSST3 (B), positive mode of HILIC, (C) and negative mode of HILIC (D) based on the UHPLC-Q-TOF/MS data of the fecal samples. 

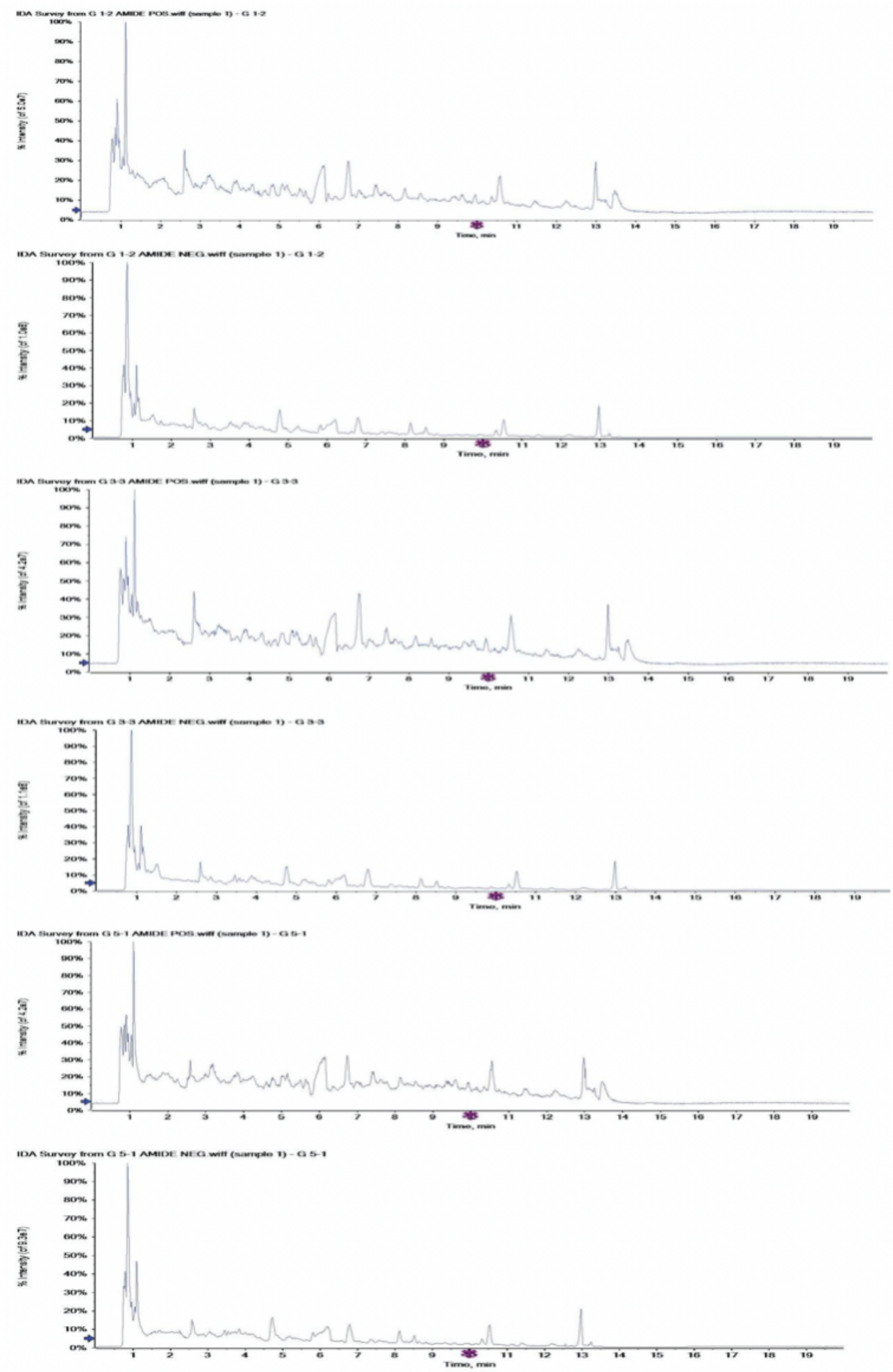

Figure 13

Representative total ion chromatograms (TICs) of fecal samples obtained by LC-MS analysis in the HILIC. 

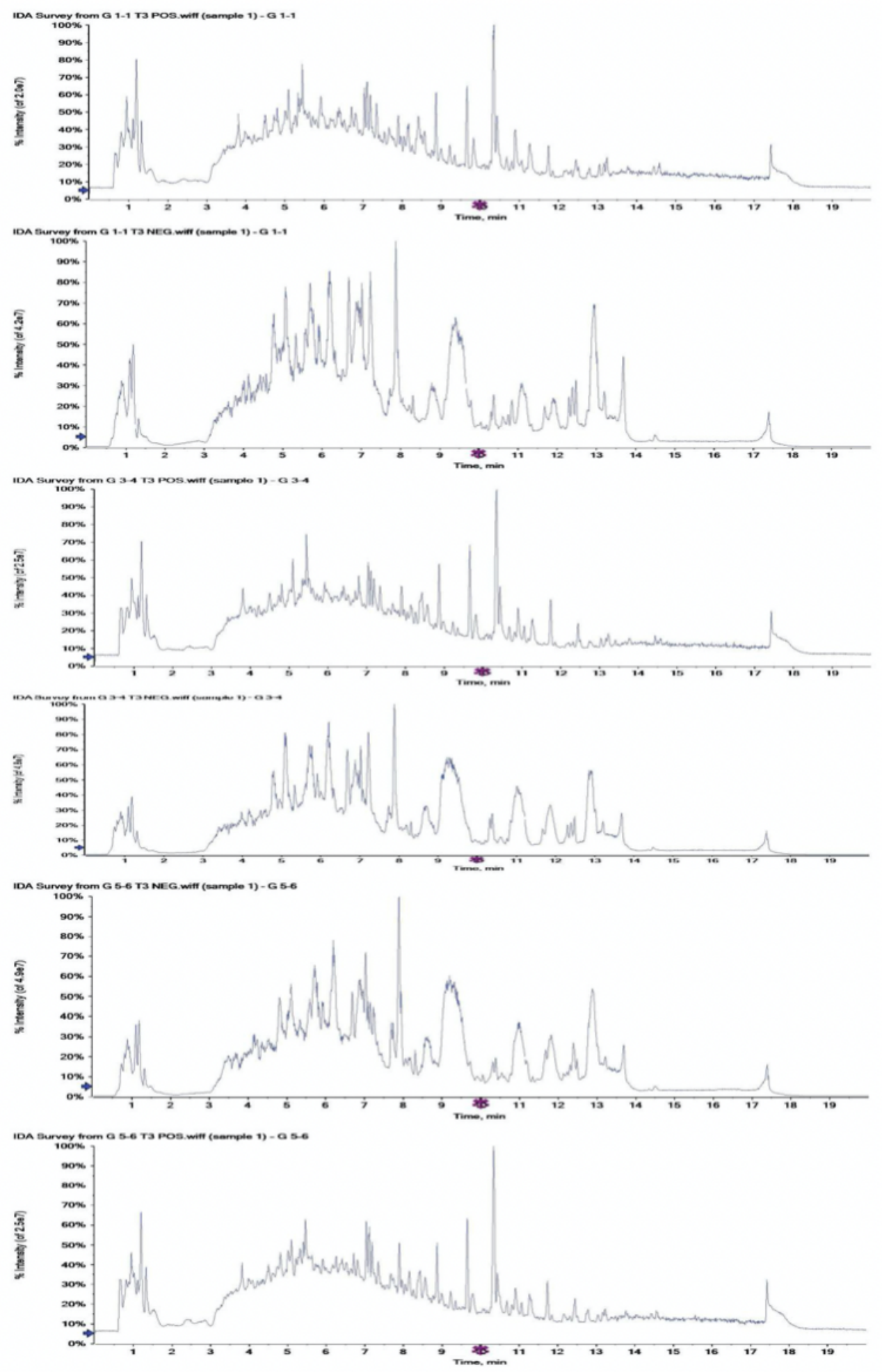

\section{Figure 15}

Representative total ion chromatograms (TICs) of fecal samples obtained by LC-MS analysis in the HSST3. 
A

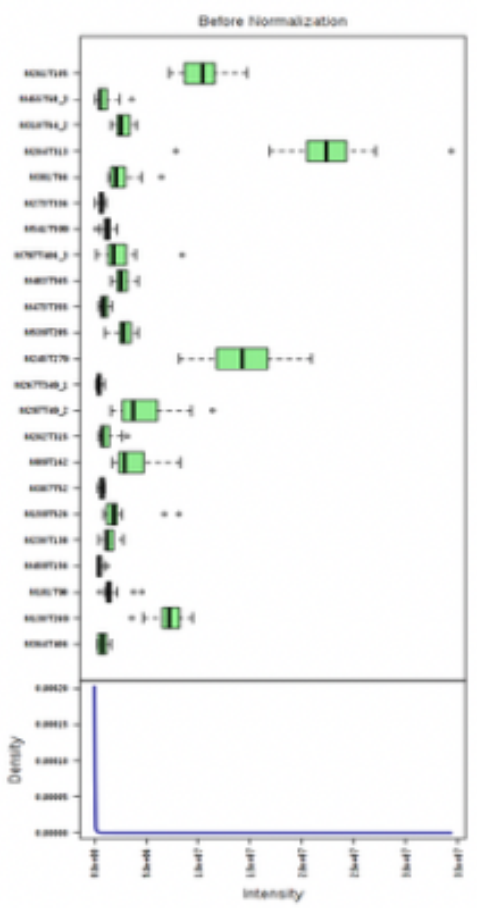

$\mathrm{C}$

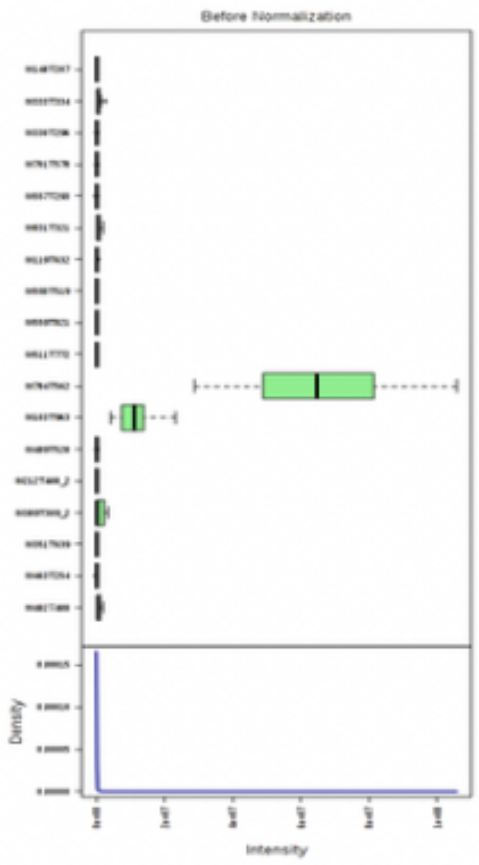

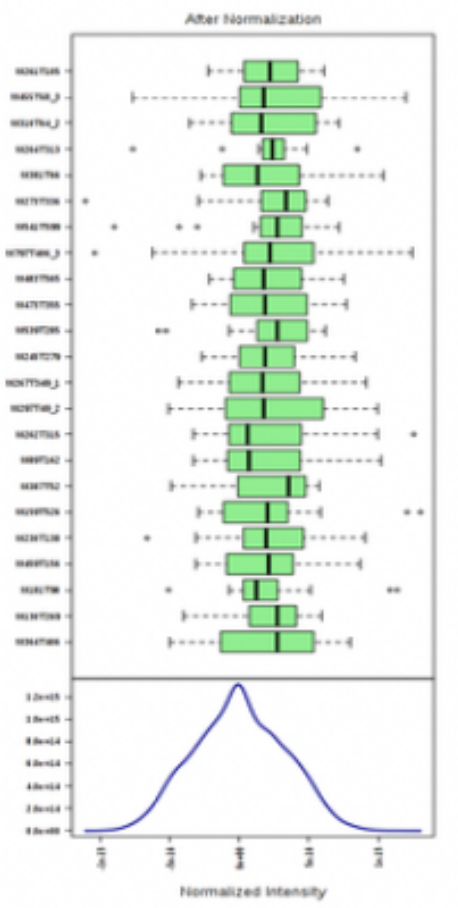

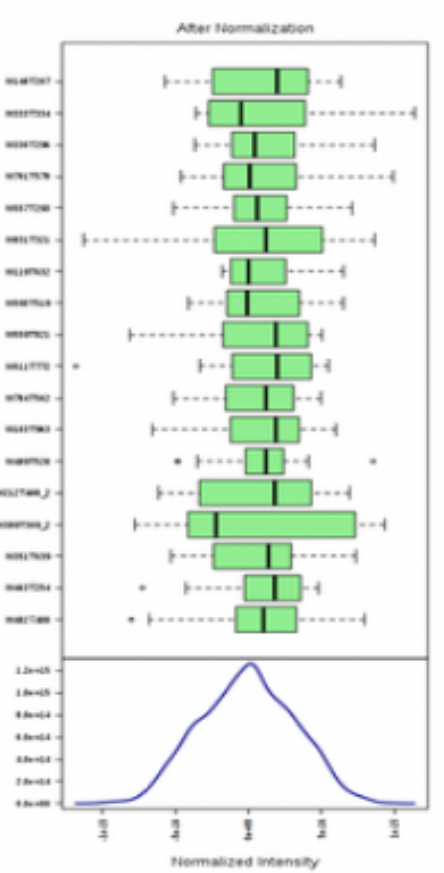

B
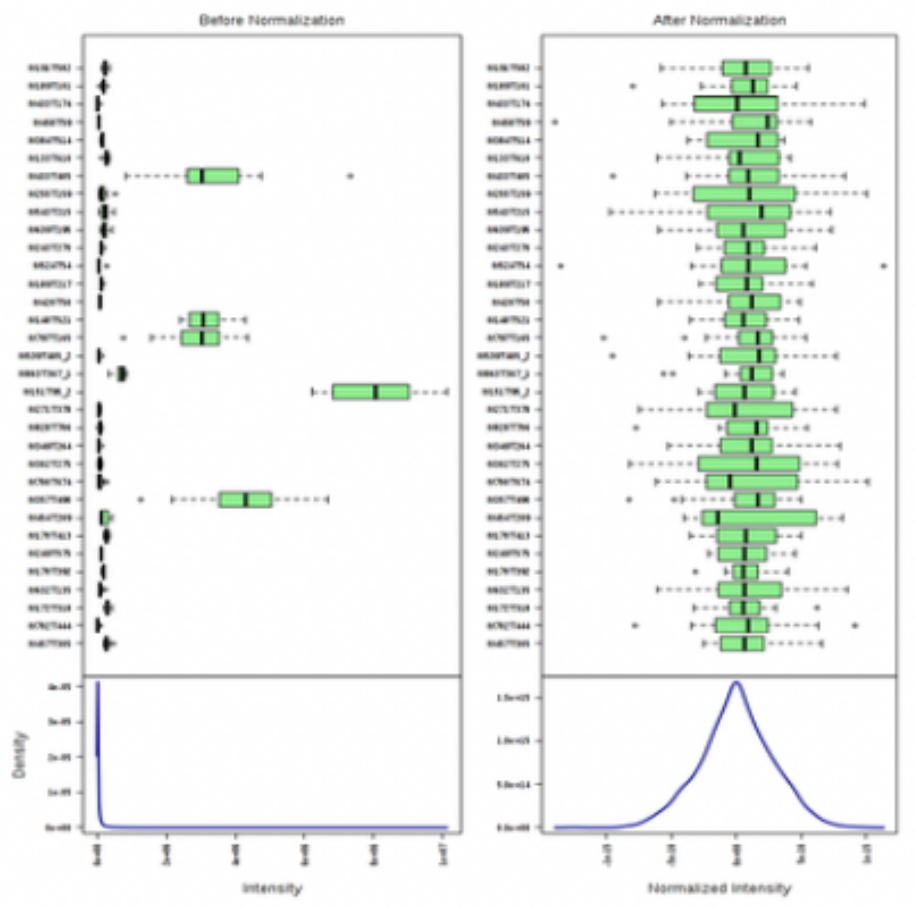

$\mathrm{D}$
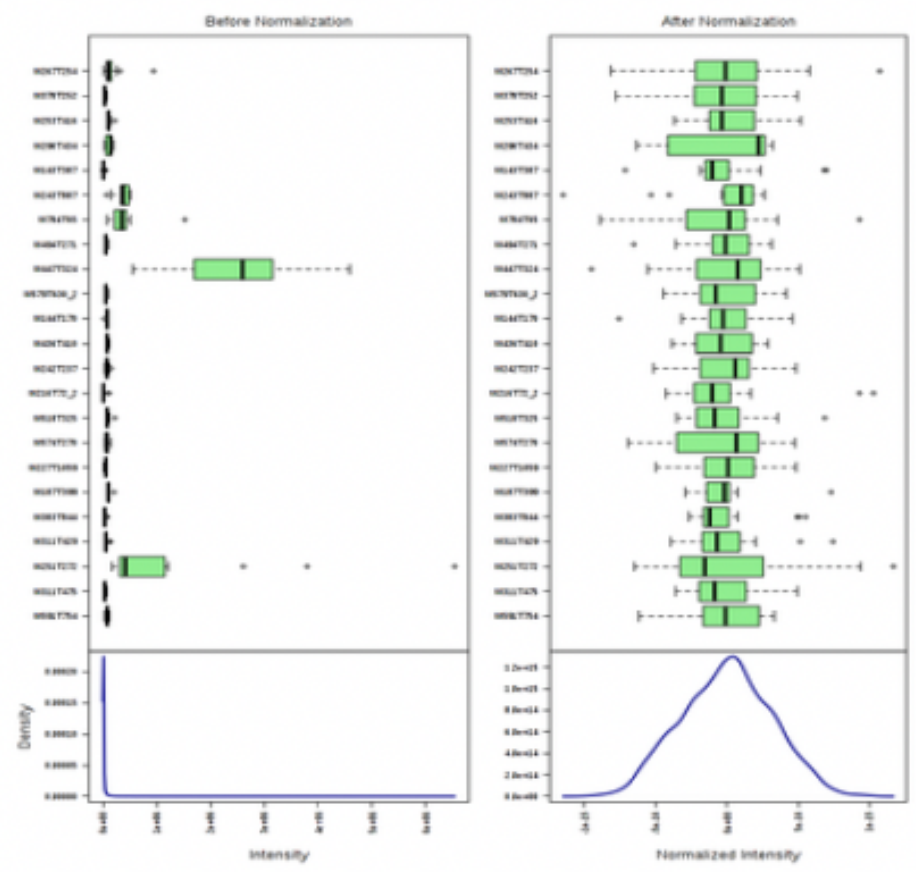

\section{Figure 17}

This graph summarizes the distribution of input data values before and after normalization: (A) Positive mode of HILIC, (B) Negative mode of HILIC, (C) Negative mode of HSST3, (D) Positive mode of HSST3. 
A

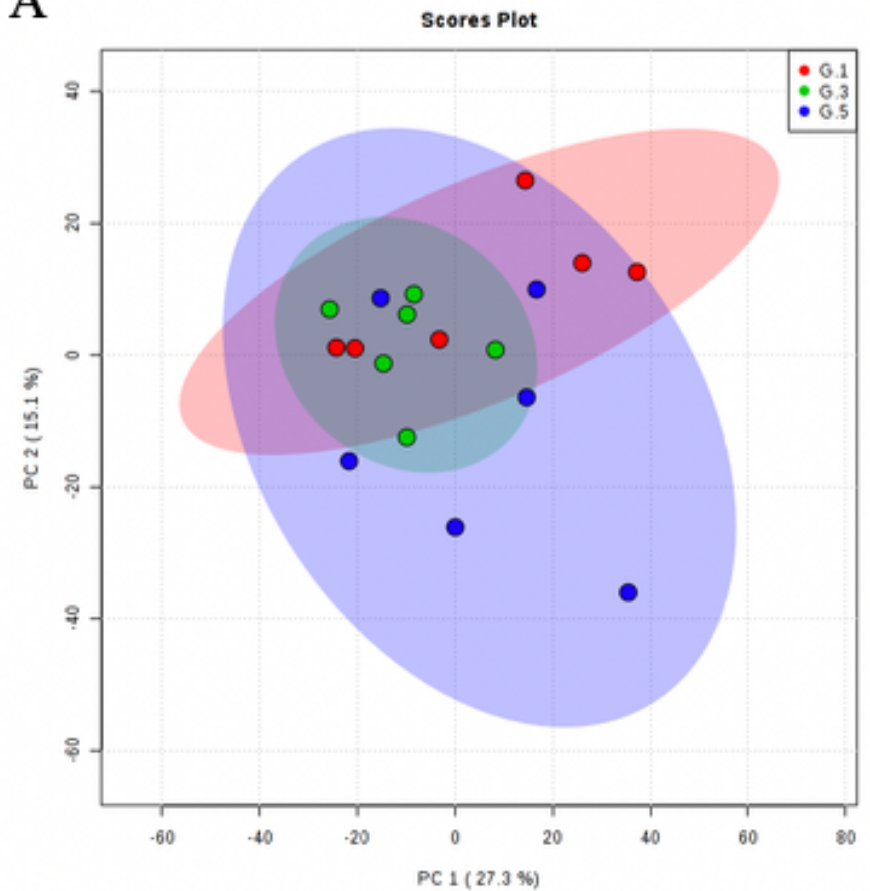

$\mathrm{C}$

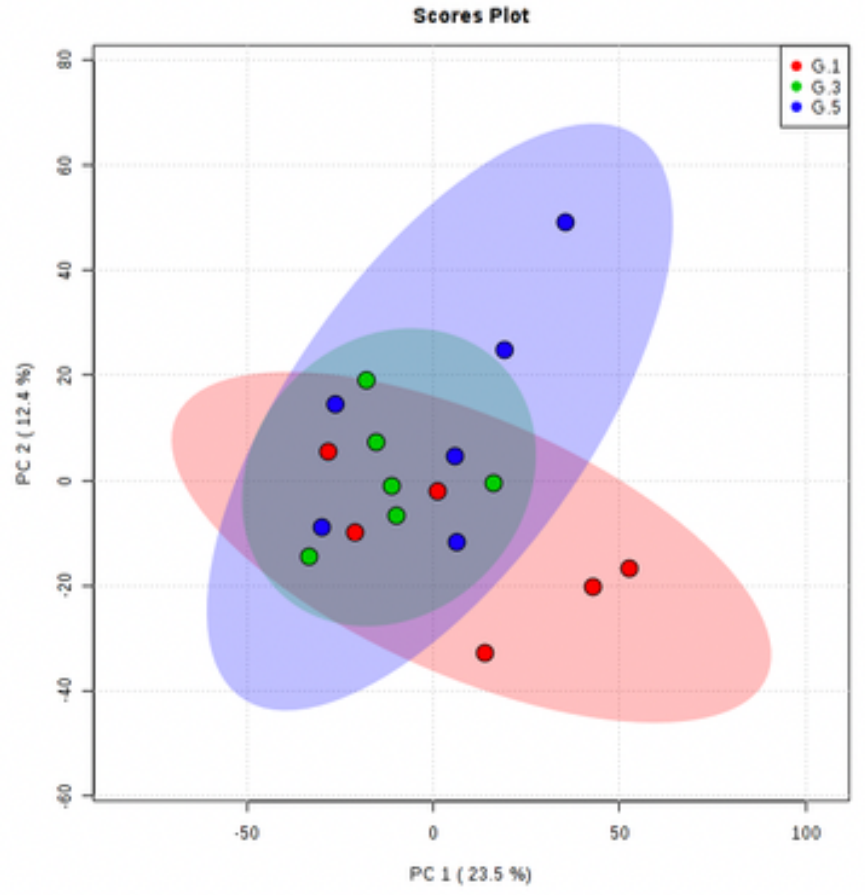

B

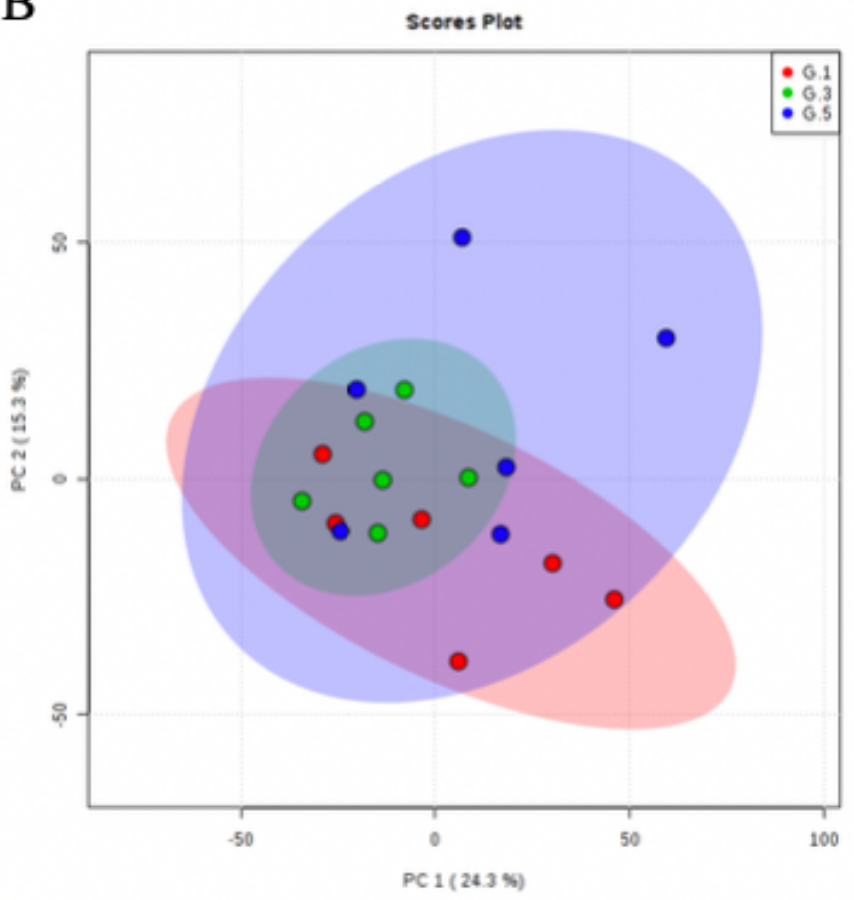

D

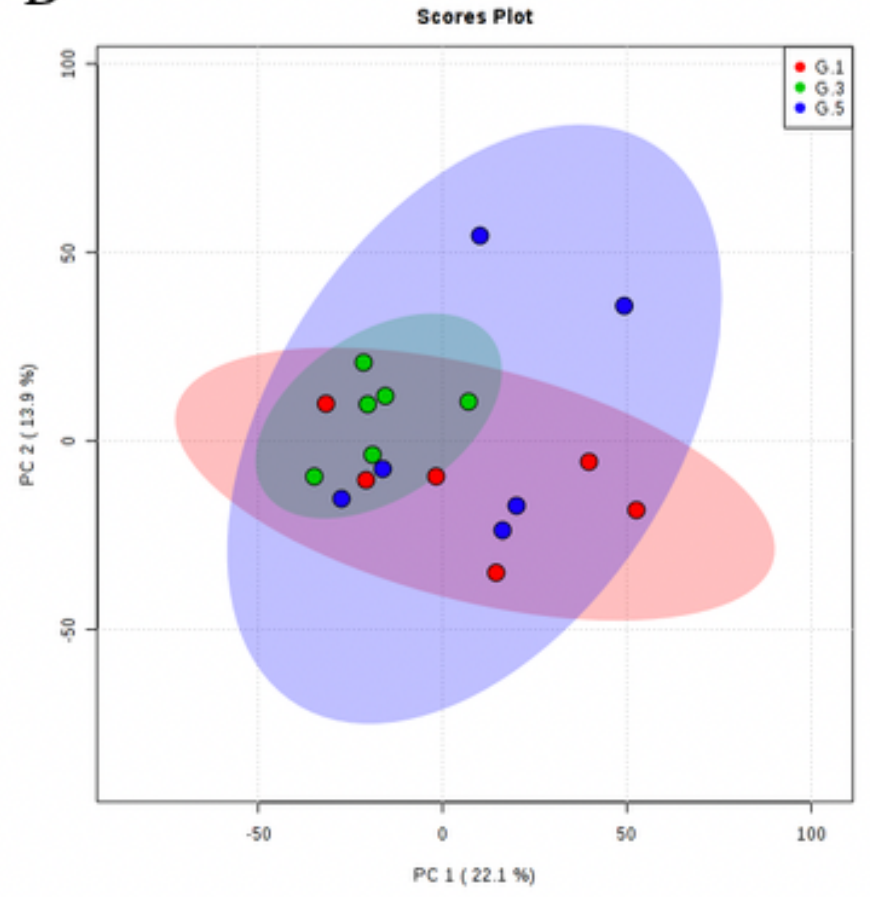

Figure 19

PCA score map derived from UHPLC-Q-TOF/MS spectra concerning G1 (red dot), G3 (green dot), G5 (blue dot) in the positive mode of HILIC (A), negative mode of HILIC (B), positive mode of HSS T3 (C), and negative mode of HSS T3 (D). 

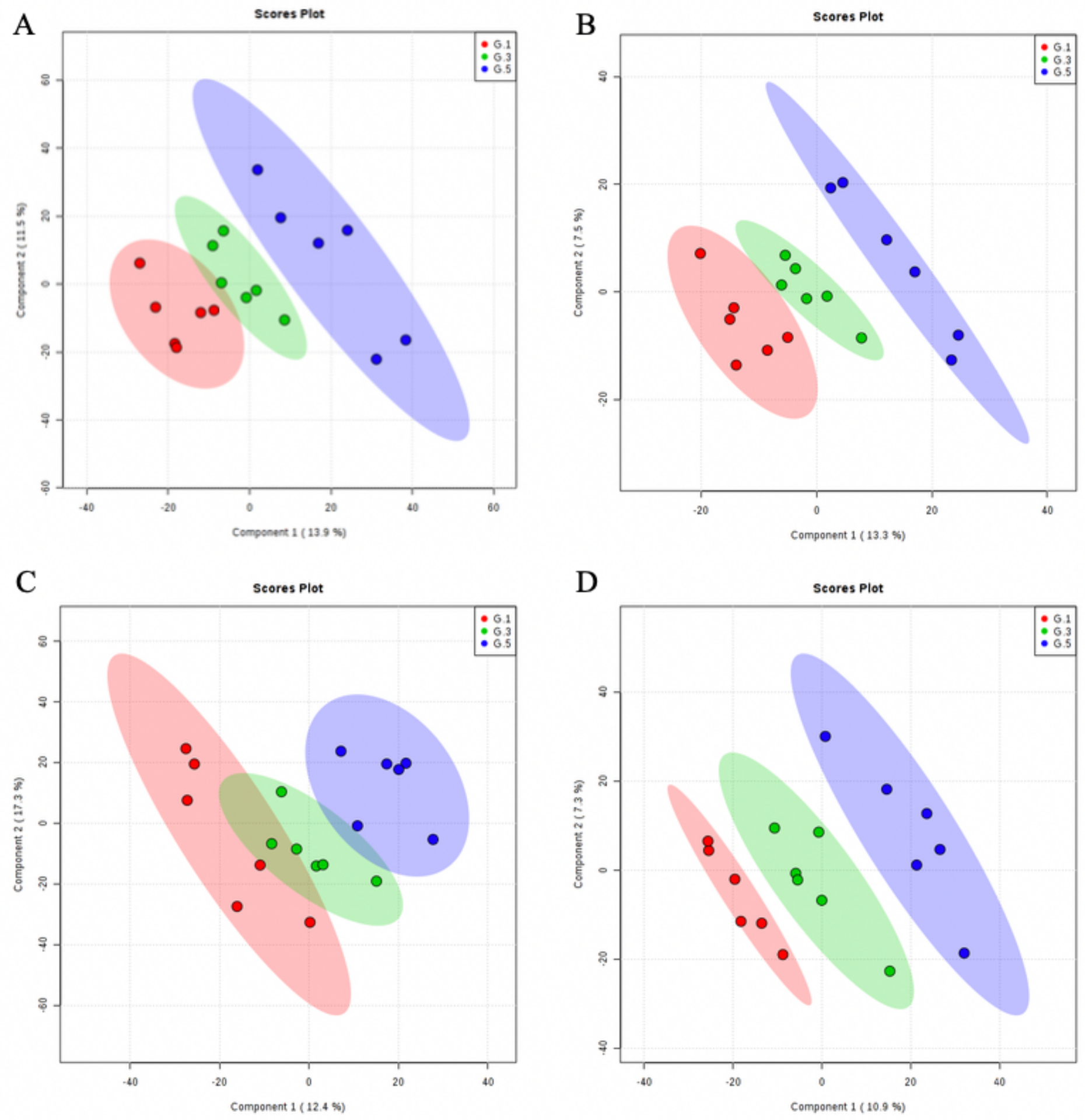

Figure 21

PLS-DA score map derived from UHPLC-Q-TOF/MS spectra concerning concerning G1 (red dot), G3 (green dot), G5 (blue dot) in the positive mode of HILIC (A), negative mode of HILIC (B), positive mode of HSS T3 (C), and negative mode of HSS T3 (D). 


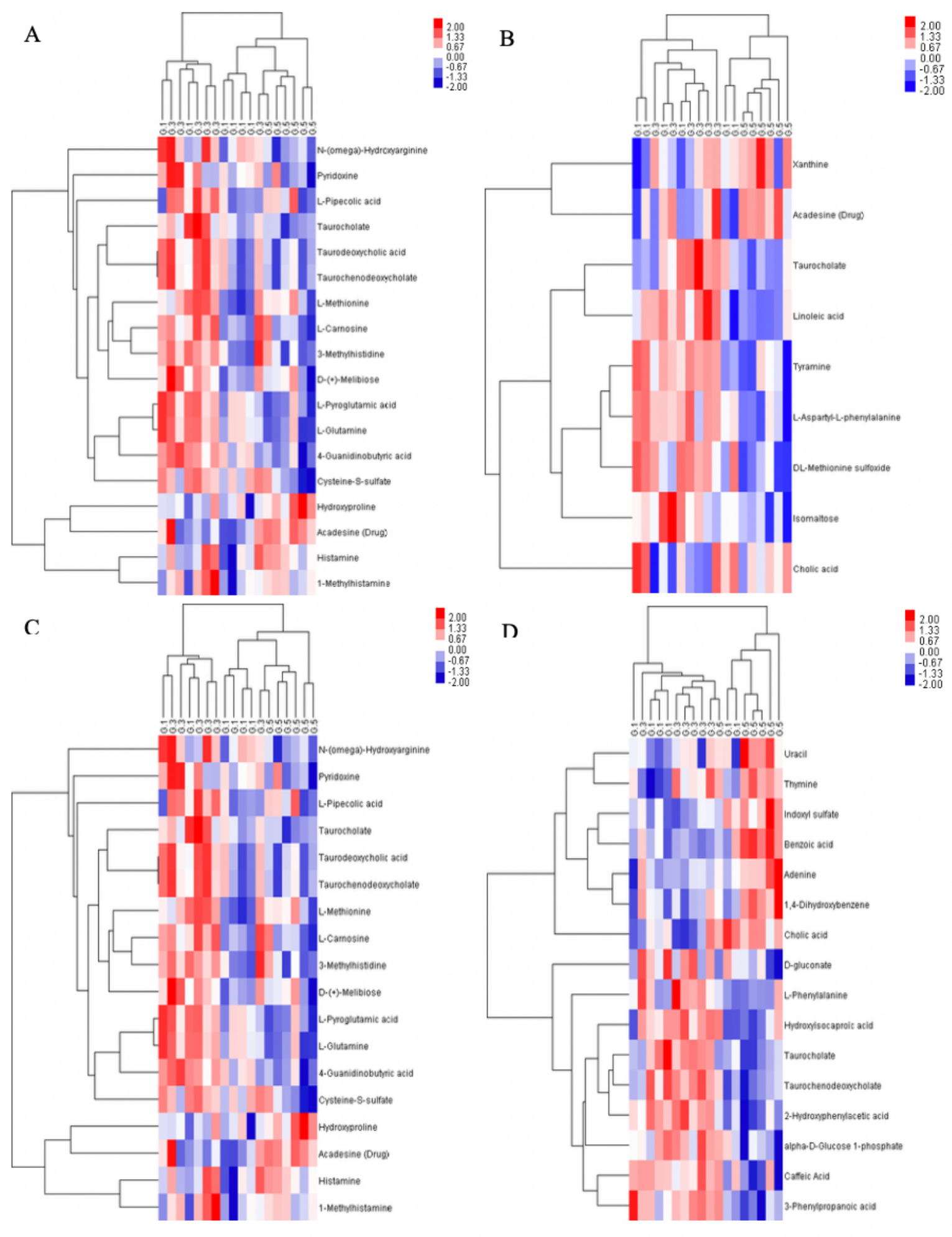

Figure 23

Hierarchically clustered heat map showing relative increase/decrease of metabolite contents and their similarities between individual samples. Columns correspond to different groups, and rows correspond to the altered metabolites. The heatmaps were constructed based on the metabolites of importance. Color key indicates metabolite expression value; blue: lowest, red: highest. (A) Positive mode of HILIC. (B) Negative mode of HILIC. (C) Negative mode of HSST3. (D) Positive mode of HSST3 


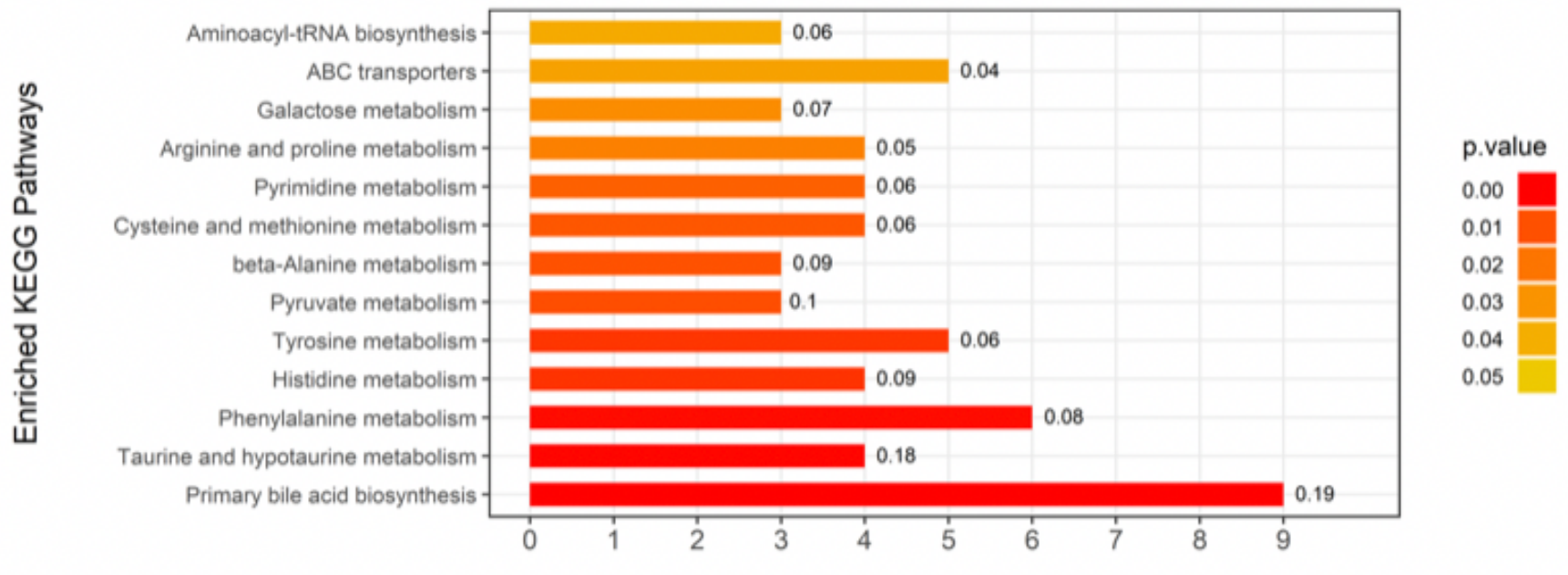

Compound Number

\section{Figure 25}

Enriched KEGG Pathways. The x-axis represents the compound number of differential metabolites contained in each KEGG pathway, and y axis represents the pathway enrichment. The label above the bar graph shows the rich factor (rich factor $\leq 1$ ). Larger sizes and darker colors represent higher pathway impact values and higher pathway enrichment. 


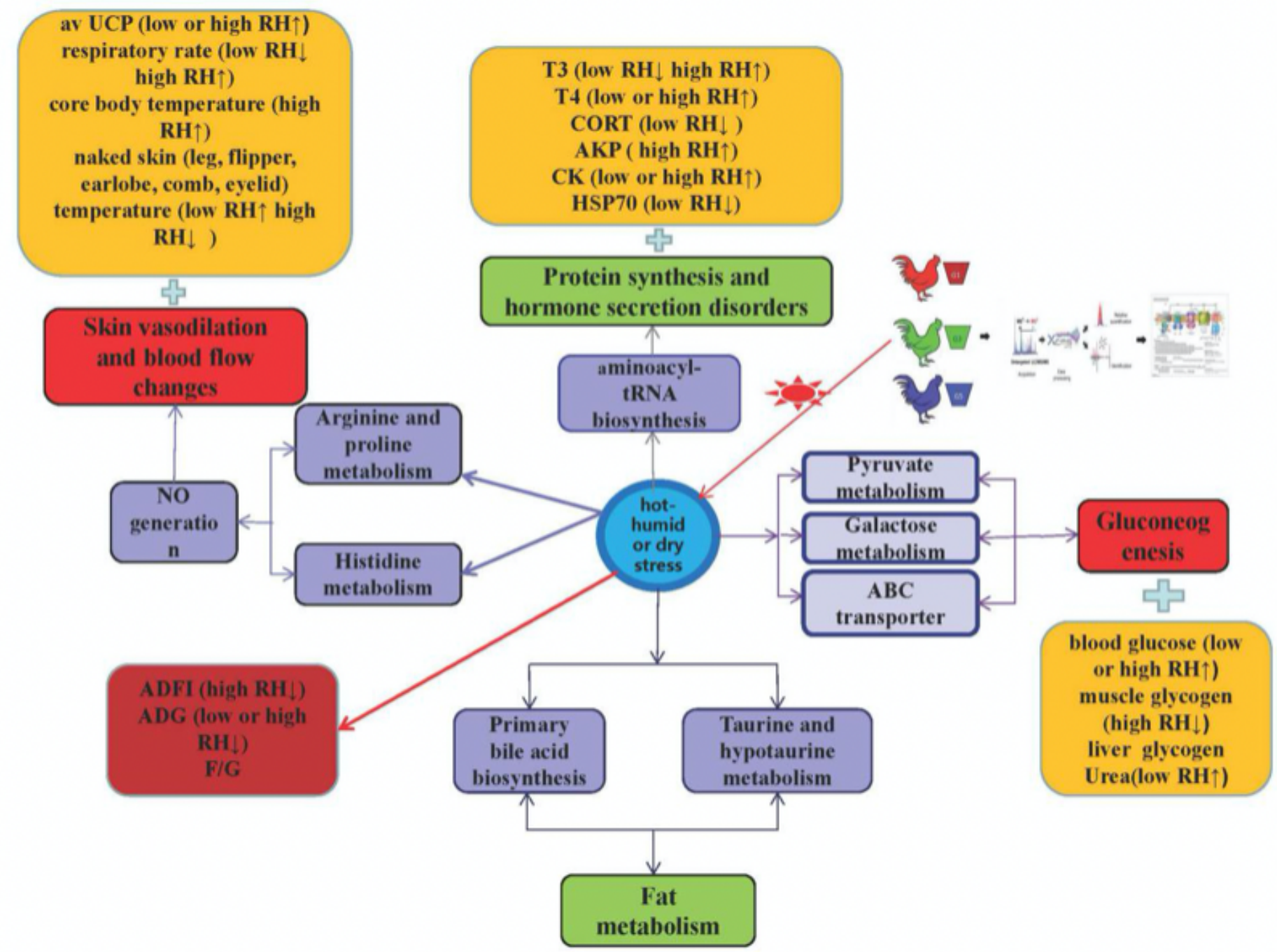

Figure 27

The metabolic network profile. 